\title{
Keys to the blow flies of Taiwan, with a checklist of recorded species and the description of a new species of Paradichosia Senior-White (Diptera, Calliphoridae)
}

\author{
Shih-Tsai Yang', Hiromu Kurahashi², Shiuh-Feng Shiao' \\ I Department of Entomology, National Taiwan University Taipei, Taiwan 2 Department of Medical Entomology, \\ National Institute of Infectious Diseases, Tokyo, Japan \\ Corresponding author: Shiuh-Feng Shiao (sfshiao@ntu.edu.tw)
}

Academic editor: P. Cerretti | Received 18 March 2014 | Accepted 11 July 2014 | Published 14 August 2014

http://zoobank.org/FD21DB91-B538-4F7A-8BE4-8E9777F17CE9

Citation: Yang S-T, Kurahashi H, Shiao S-F (2014) Keys to the blow flies of Taiwan, with a checklist of recorded species and the description of a new species of Paradichosia Senior-White (Diptera, Calliphoridae). ZooKeys 434: 57-109. doi: $10.3897 /$ zookeys.434.7540

\begin{abstract}
Blow flies (Diptera: Calliphoridae) show a great diversity in behavior and ecology, play important roles in ecosystems, and have medical and forensic importance to humans. Despite this, the taxonomy and classification of Taiwan's Calliphoridae have rarely been studied. In this study, specimens of Taiwanese calliphorids were collected and carefully studied, and all 76 species recorded in Taiwan are listed following the identification keys. Dichotomous keys to all subfamilies, tribes, genera, and species of blow flies recorded in Taiwan are provided, including 16 species that are newly recorded from Taiwan. In addition, one new species of the genus Paradichosia Senior-White is described and illustrated. We also discuss the morphological differences between the specimens of Silbomyia hoeneana Enderlein collected from China and Taiwan, a species that has only been found previously in Southern China.
\end{abstract}

\section{Keywords}

Calliphoridae, diagnostic key, new species, taxonomy

Copyright Shih-Tsai Yang et al. This is an open access article distributed under the terms of the Creative Commons Attribution License (CC BY 4.0), which permits unrestricted use, distribution, and reproduction in any medium, provided the original author and source are credited. 


\section{Introduction}

Calliphorids show great diversity in behavior and ecology. Some species parasitize terrestrial vertebrates and invertebrates such as insects, snails, amphibians, mammals, and others rely on animal carcasses or excrement for survival (Kano and Shinonaga 1968). Some calliphorid species are regarded as serious pests because they carry pathogens or parasitize livestock or humans, causing myiasis (Tumrasvin et al. 1979; Sawabe et al. 2006). Other species called carrion flies are considered important scavengers due to their necrophagous feeding behaviors (Singh et al. 1979). Some species also provide an alternative way to estimate the minimum post-mortem interval of a victim or an animal in forensic investigations (Catts and Goff 1992). Adult blow flies often visit flowers, and some species like Chrysomya megacephala (Fabricius) are pollinators of fruits (Dag and Gazit 2001). The Calliphoridae are thus important in many different fields. In this article, keys to the subfamilies, tribes, genera, and species recorded from Taiwan are provided, hopefully to help in the understanding and identification of these useful flies in studies of medical entomology, forensic entomology, agricultural pollination, and other related fields.

Only fragmentary studies have been done on the taxonomy of Taiwanese Calliphoridae. Hennig (1941) listed 46 species of Calliphoridae from Taiwan. James (1977) mentioned 34 Taiwanese species in "A Catalog of Diptera of the Oriental Region." Kurahashi (1987a) published a key to the species of Taiwan's Calliphorini and Luciliini tribes. Fan (1992) published a key to the common calyptrate flies of China, including 40 Taiwanese species. Recently, a new Lucilia species, L. taiwanensis, was described by Kurahashi and Kano (1995).

\section{Materials and methods}

Adult specimens of Taiwanese calliphorids examined in this study were collected and pinned by the authors and colleagues, and additional specimens were collected by K. Kanmiya, R. Kano, K. Matsuki, and S. Ueno. Systematics and nomenclature adopted in this paper mainly follows Rognes (1991, 1997, 2002, 2009a, 2009b, 2011a), Fan (1992), and Kurahashi and Bunchu (2011). Specimens collected by the first author were mostly deposited in the Insect Museum of National Taiwan University (NTU). Other specimens were deposited in the National Museum of Nature and Science, Tsukuba (NSMT), Bishop Museum, Honolulu (BPBM), Carnegie Museum of Natural History, Pittsburgh $(\mathrm{CMNH})$, and International Department of Dipterology, Tokyo (IDD). Some specimens are personal collection of Mr. K. Harusawa (PCKHa) as noted in the text. The terminology used in this study mainly follows that of SeniorWhite et al. (1940), Fan (1992), Triplehorn and Johnson (2005). Frons measurement and the calculation of the frons index follows Fan (1992). 


\section{Results and discussion}

Examined specimens are classified into nine subfamilies: Ameniinae, Bengaliinae, Calliphorinae, Chrysomyinae, Luciliinae, Melanomyinae, Rhiniinae, Phumosiinae, and Polleniinae. In total, 76 calliphorid species are listed herein based on our direct examinations and the literature. Among them, 16 species are newly recorded from Taiwan, with an asterisk $\left({ }^{*}\right)$ preceding each of them in the checklist. The names in this checklist include mainly the species examined in this research and partially also the species recorded in the literature. Some species that have not yet been recorded in Taiwan are also included in this key with a footnote [e.g., 'not recorded from Taiwan']. We believe these latter species have the potential to be found in future Taiwan surveys because they occur in nearby areas of the Orient.

Widespread Oriental elements share the highest proportion $(53.9 \%, 41 / 76)$ of Taiwan's calliphorid fauna, while endemic species have the second-highest $(15.8 \%$, 12/76). Australasian and Oriental-Australasian elements share 14.5\% (11/76), cosmopolitan elements 6.6\% (5/76), pantropical elements 2.6\% (2/76), Holarctic species $1.3 \%(1 / 76)$, and Palaearctic species 5.3\% (4/76).

\section{Practical keys}

\section{Key to the subfamilies of Taiwanese Calliphoridae}

$1 \quad$ Posterodorsal side of $\mathrm{R}$ stem vein of wing setose ……............................. 2

- $\quad$ Posterodorsal side of R stem vein of wing not setose ...................................3

2 Upper occiput with setulae and pollinose, without glossy submarginal band; lower facial margin not protruding much; prealar knob with erect hairs (except for tribe Phormiini); thoracic squama hairy on dorsal surface, largely lobulate, subtruncate at apex, concave on outer margin ...Subfamily CHRYSOMYINAE Upper occiput often without setulae, with bare glossy submarginal band; lower facial margin often protruding in front of vibrissal corners obviously; prealar knob bare or pubescent, without distinct hairs; thoracic squama (lower calypter) bare or pubescent on dorsal surface, usually tongue-like, narrowly rounded at apex, straight on outer margin, rarely lobulate in some species of Isomyia

Subfamily RHINIINAE

3 Anterior lappet of metathoracic spiracle with conspicuous backward-pointing tuft of long hairs; postscutellum forming definite convex swelling which is micro-rugose and sometimes shows a slight trace of a shallow median incision; female postabdomen non-telescopic, modified for deposition of grown larvae; large tachinid-like flies Subfamily AMENIINAE

- $\quad$ Anterior lappet of metathoracic spiracle bare or at most with very few inconspicuous hairs; postscutellum not at all convex or at most with a rudimentary 
trace of swelling, not as above; female postabdomen forming telescopic ovipositor, but sometimes short in larviparous species for deposition of first instar

larvae ............................................................................................. 4

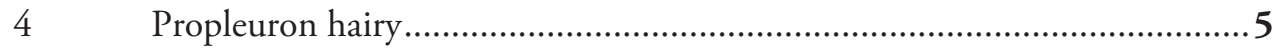

Propleuron bare ...........................................................................8

5 Posterior part of suprasquamal ridge with tuft of setulose erect hairs (posterior parasquamal tuft) on small well-defined black sclerite

Subfamily LUCILIINAE

- Posterior parasquamal tuft absent ..............................................6

6 Supraspiracular convexity clothed with long, upstanding fine hairs; anterior part of suprasquamal ridge bare; distance between right and left presutural acrostichal bristles $(a c)$ rather large, almost equal to distance between presutural $a c$ and dorsocentral bristles $(d c)$; mesothoracic spiracle rather large, sometimes swollen; thoracic squama bare.

Subfamily PHUMOSIINAE, Caiusa Surcouf

- Supraspiracular convexity bare or pubescent ..................................... 7

7 Hairs on thoracic squama widely distributed .... Subfamily CALLIPHORINAE Thoracic squama bare, or only few hairs fragmentarily distributed....

Subfamily MELANOMYINAE

8 Prosternum usually hairy; thorax not clothed in golden curly hairs; eyes dichoptic, eyes widely separated in both male and female; proboscis short and stout, boat-shaped; body at least partly yellowish

Subfamily BENGALIINAE, Bengalia Robineau-Desvoidy

- $\quad$ Prosternum bare; thorax usually with golden curly hairs, sometimes lacking; head usually holoptic or subholoptic in males, sometimes dichoptic

Subfamily POLLENIINAE

\section{Subfamily AMENIINAE}

\section{Key to the tribes and genera of AMENIINAE}

1 Head almost always with a very large facial carina; propleuron and prosternum almost always hairy; hind tibia with apical posteroventral bristle $(p v)$; outer posthumeral bristle $(p h)$ situated mesad of presutural bristle $(p r s)$; ventral surface of costa setulose between apices of subcostal $\left(\mathrm{Sc}_{\mathrm{c}}\right)$ and first longitudinal $\left(\mathrm{R}_{1}\right)$ veins.

Tribe Ameniini, Silbomyia Macquart

- Head without facial carina; propleuron bare; prosternum bare, sometimes hairy; hind tibia without apical $p v$; outer $p h$ situated laterad of prs; ventral surface of costa bare between apices of veins $S_{c}$ and $R_{1}$ 


\section{Tribe Ameniini}

\section{Key to the species of Silbomyia}

$1 \quad$ Facial carina longer and distinctly fusiform, slightly longer than distance from lunule to anterior ocellus; male antennae longer than in female, third segment of antenna ( $\mathrm{AS}_{3}$; first flagellomere) in male at least 4 times as long as $\mathrm{AS}_{2}$ (pedicel); postorbits yellow or silvery yellow..... S. cyanea (Matsumura)

- Facial carina short, and roof-like, shorter than distance from lunule to anterior ocellus; antennae about equal in length in both sexes, $\mathrm{AS}_{3}$ not more than 3.9 times as long as $\mathrm{AS}_{2}$; postorbits silvery white

2 One or both of third tergite $\left(\mathrm{T}_{3}\right)$ and $\mathrm{T}_{4}$ almost always with one pair or more of strong median discal setae; color usually dark blue to violet, sometimes green; male frontal stripe (interfrontal area) no more than 3 times as wide as one parafrontal; distance between eyes at lower margin subequal or slightly broader than that at vertex in frontal view in male; lobe of fifth sternite $\left(\mathrm{ST}_{5}\right)$ shorter than basal part .....

S. sauteri Enderlein

- $\quad$ Third tergite and $\mathrm{T}_{4}$ without or only $\mathrm{T}_{3}$ with one pair of very weak discal setae; color green to blue; male interfrontal area about 3.5 times as wide as one parafrontal; distance between eyes at lower margin slightly narrower than that at vertex in frontal view in male; lobe of $\mathrm{ST}_{5}$ longer than basal part ... S. hoeneana Enderlein

\section{Tribe Catapicephalini}

Key to the species of Catapicephala

1 Eyes hairy C. dasyophthalma Villeneuve

- $\quad$ Eyes bare. 2

2 Antenna orange; tomentum on face golden C. ruficornis Villeneuve

- $\quad$ Antenna entirely fuscous; tomentum on face grey; $T_{4}, T_{5}$ brilliant metallic blue; silver white pollinosity on lateral and ventral sides of $\mathrm{T}_{5}$ extending to dorsal side, visible in dorsal view; fronto-orbital bristles (ors) $0+1$ in male, $2+1$ in female.

C. splendens Macquart

\section{Subfamily CALLIPHORINAE}

\section{Key to the genera of CALLIPHORINAE}

1 Presutural ac usually 1, rarely absent; facial carina more or less developed..... ..Polleniopsis Townsend

- $\quad$ Presutural ac 2; facial carina absent 
2 Head dichoptic in both male and female; $\mathrm{AS}_{3}$ elongate, more than 4 times as long as $\mathrm{AS}_{2}$; presutural intra-alar bristles (ia) absent.....Tainanina Villeneuve Head holoptic or subholoptic in male, dichoptic in female; $\mathrm{AS}_{3}$ variable in length; presutural $i a$ present or absent..........................................................

3 Presutural ia absent; eyes in male subholoptic; male hypopygium prominently swollen, metallic................ Aldrichina Townsend, A. grabami (Aldrich)

- $\quad$ Presutural ia present; eyes in male holoptic; male hypopygium not remark-

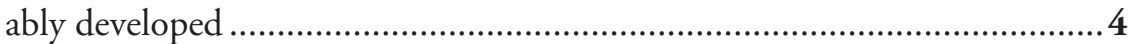

4 Body small- to medium-sized; distance between rows of right and left presutural $a c$ rather small (fig. $1 b$ in Kurahashi 1970); male paraphallus with wide, sickle-like tip

...... Bellardia Robineau-Desvoidy (Kurahashi (1987b) treat it in genus Onesia) Body large-sized; distance between rows of right and left presutural $a c$ rather large (fig. 1a in Kurahashi 1970); male paraphallus with slender tip....

Calliphora Robineau-Desvoidy

\section{Key to the species of Calliphora}

1 Postgena clothed with orange or pale yellow hairs, or intermixed with black ones; mesothoracic spiracle fuscous black C. vomitoria (Linnaeus)

- $\quad$ Postgena clothed wholly with black hairs 2

2 Mesothoracic spiracle yellowish brown to orange .... C. nigribarbis Vollenhoven

- Mesothoracic spiracle black or blackish brown C. pattoni Aubertin

\section{Key to the species of Bellardia}

1 Body length less than $6 \mathrm{~mm} ; \mathrm{R}_{5}$ cell closed at wing margin; vein $\mathrm{M}_{1+2}$ gently curved, with dull angle................................................ B. menechma (Séguy)

- $\quad$ Body length longer than $8 \mathrm{~mm} ; \mathrm{R}_{5}$ cell open at wing margin; vein $\mathrm{M}_{1+2}$ bent with a right angle

B. pubescens (Macquart)

\section{Key to the species of Tainanina}

1 Fronto-orbital bristles 0 in male, $2+1$ in female .... T. sarcophagoides (Malloch)

- $\quad$ Fronto-orbital bristles $1+1$ in both sexes ....... T. pilisquama (Senior-White) 


\section{Key to the species of Polleniopsis}

1 Presutural ia present, abdomen black, densely covered with yellowish gray or golden dusting, strongly tessellated; facial carina well developed; outer $p h$ present P. toxopei (Senior-White)

- $\quad$ Presutural ia absent, abdomen black, with bluish or bronzy tinge, silver-gray dusted; facial carina poorly developed; outer $p h$ absent

P. dalatensis Kurahashi

\section{Subfamily MELANOMYINAE}

\section{Key to the genera of MELANOMYINAE}

$1 \quad$ Eye bare; ia 0 (male) or 1 (female) +2 ; outer $p h$ present; $a c 2+3$; $d c 3+3$; sternopleural bristle $(s t) 1+1$; body yellowish brown, thorax with gray dusting; pronotum with 5 black vertical stripes; meso- and metathoracic spiracle yellowish white; leg yellowish, with blackish tarsus; 6.5-7.5 mm

Tricycleopsis Villeneuve, $T$. paradoxa Villeneuve

- $\quad$ Eye hairy, or with sparse short hairs, or bare; st usually 2+1; other characters not as above 2

2 Eye with distinct, dense hairs; body almost all black

Paradichosia Senior-White

- $\quad$ Eye with sparse short hairs or bare ......................................................... 3

3 At least part of body yellow; scutellum with at least apex yellowish; $\mathrm{T}_{1+2}$ and $\mathrm{T}_{3}$ testaceous yellow; legs testaceous except for fuscous tarsi.

Gymnadichosia Villeneuve, G. pusilla Villeneuve

- $\quad$ Body blackish; scutellum entirely black; abdomen and legs black except for brownish tibia Pollenomyia Séguy, $P$. sinensis Séguy

\section{Key to the species of Paradichosia}

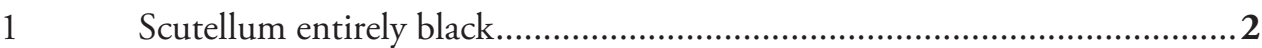

- $\quad$ Scutellum with at least apex yellowish......................................................... 3

2 Hind tibia with submedian anterodorsal bristle $(a d)$ more than 3 times as long as tibial diameter; hind tarsus with dorsal hairs longer than usual, forming a short fringe; third sternite ( $\left.\mathrm{ST}_{3}\right)$ of male with tuft of long hairs.

P. dubia Malloch [not recorded from Taiwan]

- Submedian ad of hind tibia no more than 3 times as long as tibial diameter; dorsal hairs of hind tarsus not longer than usual; male $\mathrm{ST}_{3}$ with tuft of very short hairs...... P. lui sp. n. 
3 Fore coxa yellow in front; femora entirely fulvous yellow; none of the hind tibial bristles exceptionally long or slender in both sexes

P. crinitarsis Villeneuve

- $\quad$ Fore coxa fuscous in front; femora fulvous yellow or dark brown; 1 or 2 of the hind tibial bristles in male 2-3 times as long as tibial diameter.

P. nigricans Villeneuve

\section{Subfamily LUCILIINAE}

\section{Key to the genera of LUCILIINAE}

1 Supraspiracular convexity bare or pubescent .... Lucilia Robineau-Desvoidy

- Supraspiracular convexity clothed with long, erect, fine hairs.

Hemipyrellia Townsend, H. ligurriens (Wiedemann)

\section{Key to the species of Lucilia}

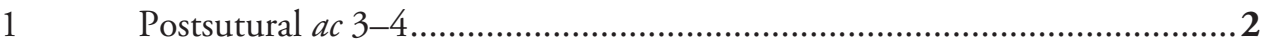

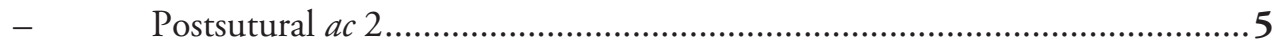

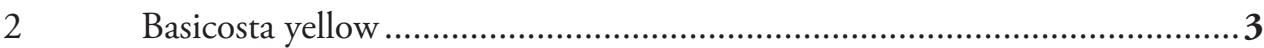

- Basicosta fuscous to black .................................................................... 4

3 Abdomen usually metallic green, more or less oval, not arched in profile, without tuft of long hairs on sternites in male; female having metallic green to gold tinged abdomen with sparse pruinosity; $5-8$ occipital hairs (occ) in female ........................................................................ sericata (Meigen)

- $\quad$ Abdomen coppery, elongate, arched in profile, with tufts of long hairs on sternites in male; hypopygium prominent; female having coppery abdomen with dense pruinosity; 1 occ in female .................. L. cuprina (Wiedemann)

4 Body metallic purple or blue.................... L. taiwanica Kurahashi \& Kano Body metallic green ................................................... L. hainanensis Fan

5 Anterior pair of postsutural $a c$ usually more advanced than second pair of postsutural $d c ; \mathrm{T}_{3}-\mathrm{T}_{5}$ without dark marginal band posteriorly; mid tibia with 1 ad in both sexes

L. porphyrina (Walker)

- $\quad$ Anterior pair of postsutural ac level with or slightly posterior to second pair of postsutural $d c ; \mathrm{T}_{3}-\mathrm{T}_{5}$ with dark marginal band posteriorly; mid tibia with 1 ad in male, 2 ad in female.

6 First postsutural $a c$ more posterior, on posterior $2 / 5$ part of postsutural area; distance between first postsutural $d c$ and second postsutural $d c$ twice as long as distance between second postsutural $d c$ and third postsutural $d c$; large size flies, body length usually more than $10.0 \mathrm{~mm}$

L. sinensis Aubertin 
- $\quad$ First postsutural ac normal, on anterior 3/5 part of postsutural area; distance between first postsutural $d c$ and second postsutural $d c$ as long as distance between second postsutural $d c$ and third postsutural $d c$.... Alar squama (upper calypter) creamy, with tuft of yellowish white hairs at inner lower margin; thoracic squama pale, brownish on disc.

L. bazini Séguy

- Alar squama fuscous brown, sometimes more or less paler at inner $1 / 2$, but usually with tuft of blackish-brown, sometimes brown, hairs at inner lower margin .. 8 Posterior surface of postgena clothed with yellow hairs; parafacilia narrow, invisible in profile, about $1 / 2-2 / 3$ of the width of $\mathrm{AS}_{3}$, golden yellow dusted, often darkened above. L. calviceps Bezzi

- $\quad$ Posterior surface of postgena clothed with black hairs; parafacilia rather broad, at least as broad as the width of $\mathrm{AS}_{3}$, gray dusted, rarely with yellow tinge

L. papuensis Macquart

\section{Subfamily BENGALIINAE}

\section{Key to the species of Bengalia}

$1 \quad$ Prealar knob pointed; fourth sternite $\left(\mathrm{ST}_{4}\right)$ with 1 pair of long and strong median marginal bristles $(m b)$ in male; abdomen very slightly pollinose; body small- to medium-sized; mesonotum blackish on disc.... B. calilungae Rueda

- $\quad$ Prealar knob rounded; $\mathrm{ST}_{4}$ without strong $m b$ in male; abdomen slightly to heavily tessellated; body medium- to large-sized................................. 2

2 Fifth tergite without discal bristles; hind tibia never fringed in male ...........3

- $\quad$ Fifth tergite with 1 pair of discal bristles; hind tibia more or less fringed in male, sometimes not very dense, covered with row of 3-7 fine long anter-

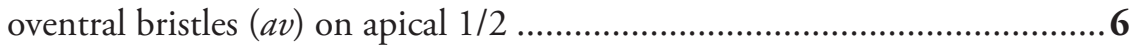

3 Vibrissa far above oral margin, distance between vibrissa and oral margin larger than wide of $\mathrm{AS}_{3}$; clypeus strongly projecting forward; posterior margin of eye somewhat concave at middle; fore tibia in male with $5+2$ ventral spines; hairs on pteropleuron wholly yellowish (Fig. 1)

B. torosa (Wiedemann)

- Vibrissa level with oral margin; clypeus less strongly projecting; posterior margin of eye straight, not concave at middle; fore tibia in male with 3 ventral spines; hairs on pteropleuron wholly whitish yellow or with some black hairs present at least on upper part ......................................................4

4 Epaulet (tegula) blackish, with hind margin yellowish; pteropleuron hairs totally whitish yellow (Fig. 2)

B. chekiangensis Fan

- $\quad$ Epaulet yellowish; pteropleuron hairs not totally yellowish 5

5 Fifth tergite black, tessallated; mesopleuron bicolored, yellow on upper 1/3, yellow upper part distinct from lower 2/3 blackish; pteropleuron largely 


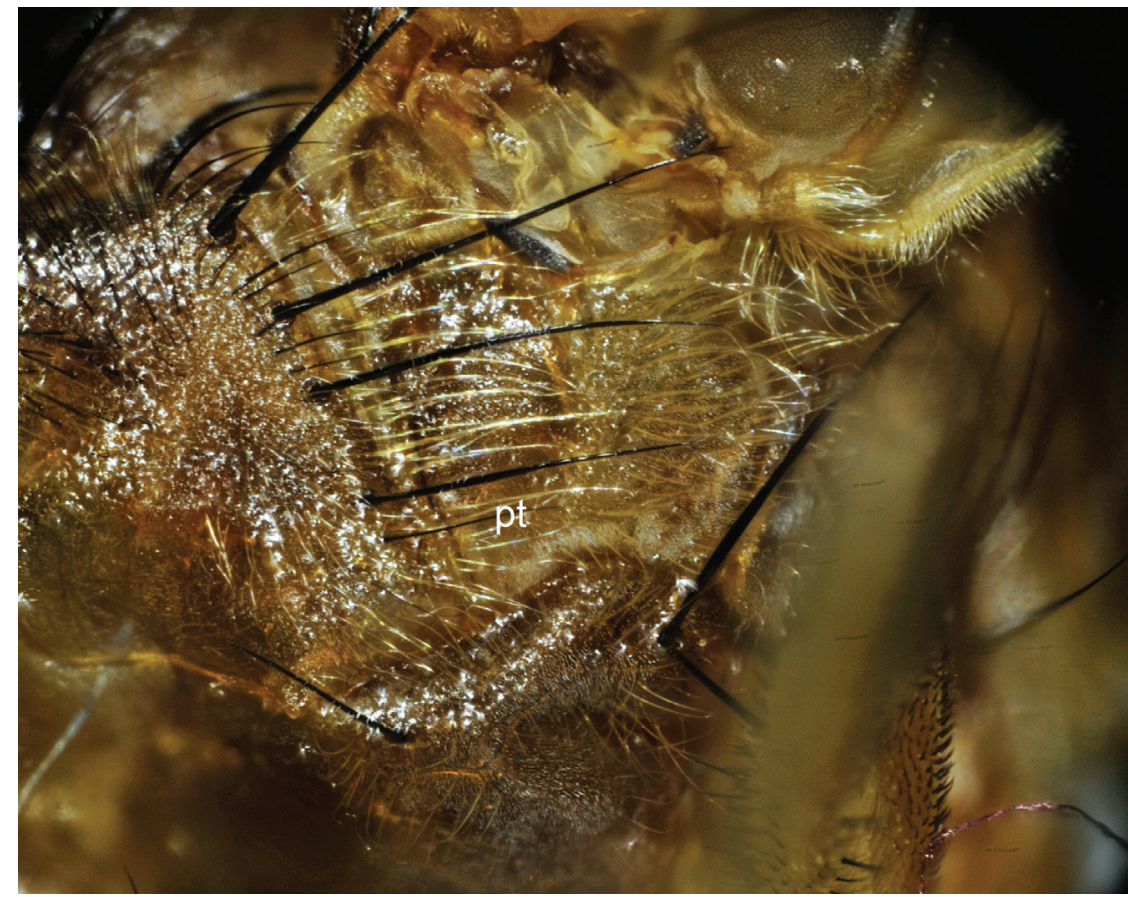

Figure I. Pteropleuron (pt) of Bengalia torosa (Wiedemann), hairs on pteropleuron are wholly yellowish.

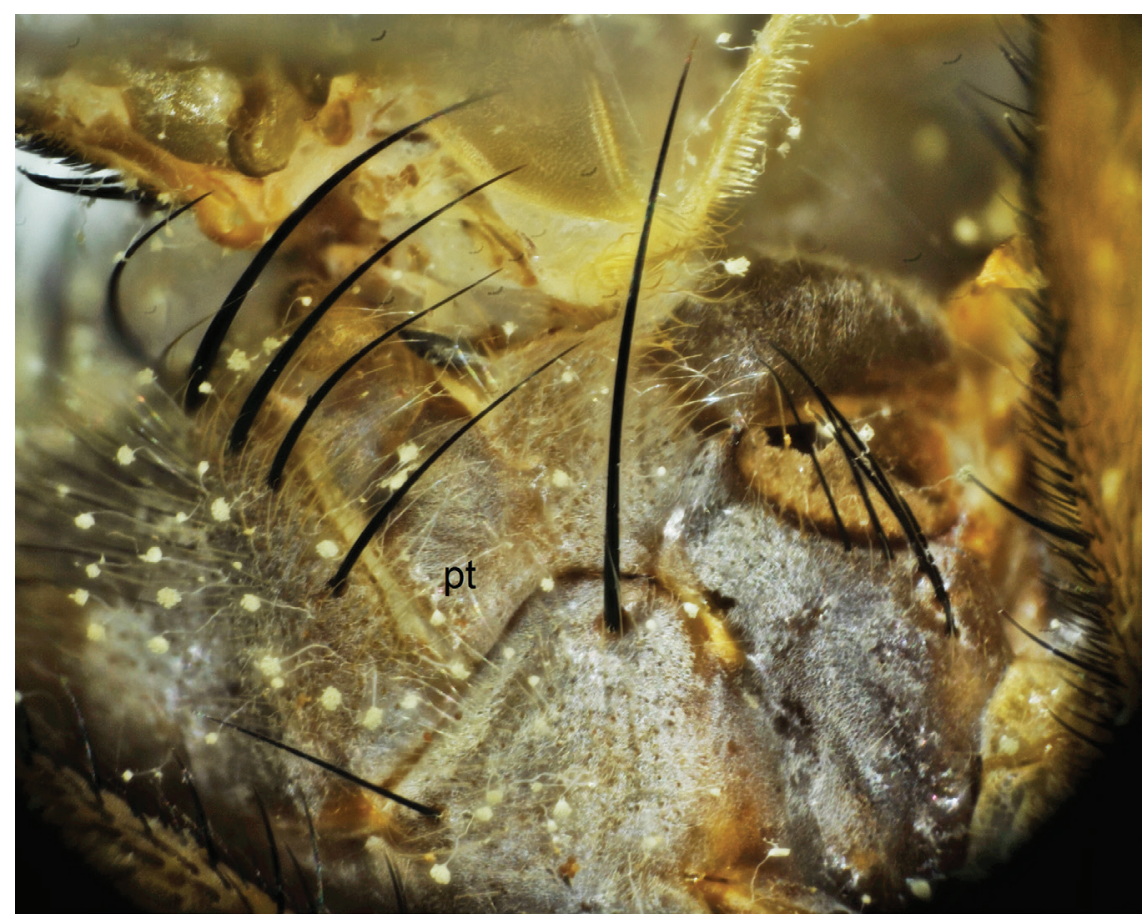

Figure 2. Pteropleuron (pt) of Bengalia chekiangensis Fan, hairs on pteropleuron are totally whitish yellow. 
covered with black hairs (Fig. 3); stenopleuron also mostly blackish haired; femora largely fuscous

B. escheri Bezzi

- $\quad$ Fifth tergite yellowish brown with black marginal band; mesopleuron yellowish, but more or less brownish on lower part; pteropleuron largely covered with yellow hairs except for tuft of several blackish hairs (Fig. 4); sternoplerual hairs yellow except for a tuft of black ones; femora yellow....

B. fuscipennis Bezzi

Pteropleuron mostly clothed in yellow hairs, less than 15 black hairs present on upper part (Fig. 5); $d c 2+4$; mid tibia not typically fringed in male; fore tibia with 2-3 long and 2-5 short stout spines on anteroventral surface in male; body $8-11 \mathrm{~mm}$.

B. varicolor (Fabricius)

- $\quad$ Pteropleuron mostly or largely clothed in black hairs, at least 20 hairs on upper part black (Fig. 6); $d c 1-3+4$; mid tibia with or without fringe in male; fore tibia without spines, at most with several small spines on anteroventral surface; body $11-15 \mathrm{~mm}$ Projection of male $\mathrm{ST}_{5}$ rounded with small indentation; mid tibia double-fringed on apical $2 / 3$ of posteroventral surface in male; $T_{5}$ in female without indentation in median part of posterior margin; $d c 3+4$.

B. emarginata Malloch

- $\quad$ Fifth sternite in male with two-branched projection; mid tibia not typically fringed in male; $\mathrm{T}_{5}$ in female with small indentation in median part of posterior margin; $d c 1-2+4$

B. taksina (Lehrer)

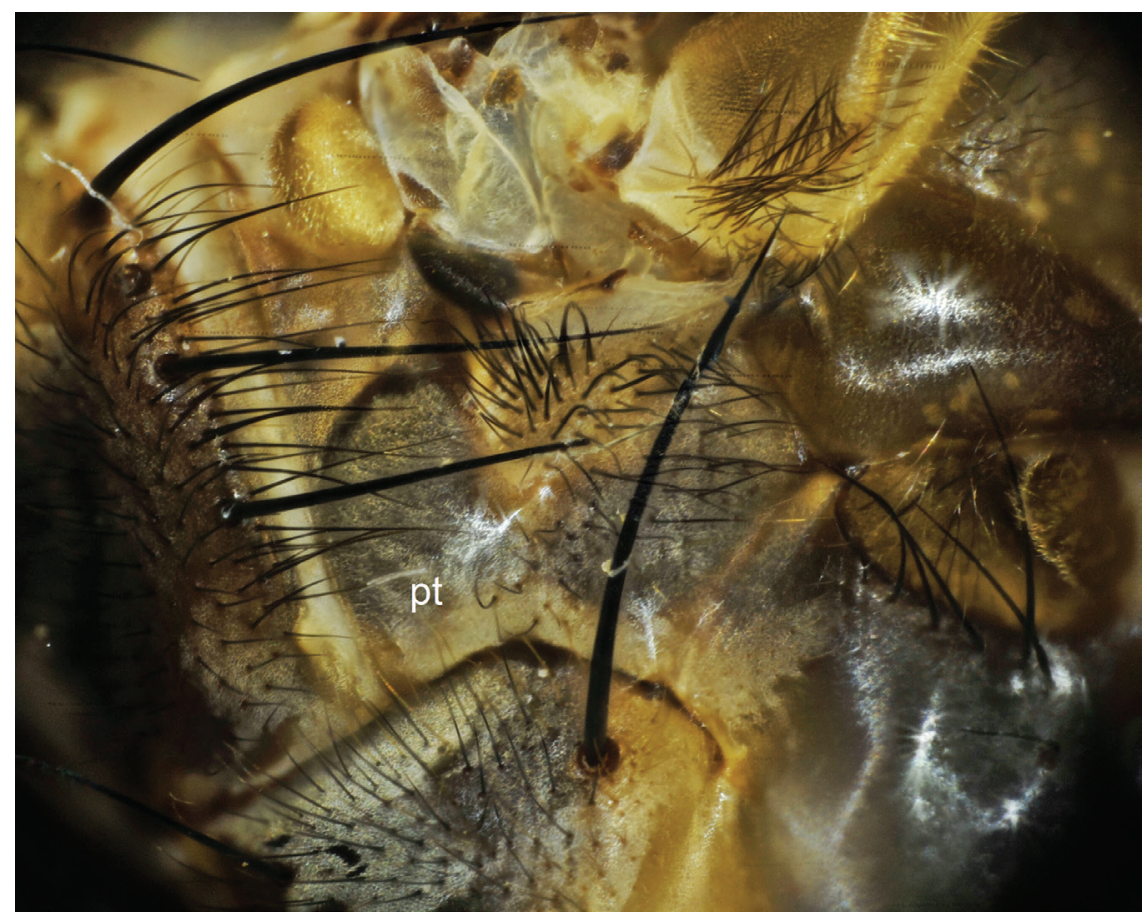

Figure 3. Pteropleuron (pt) of Bengalia escheri Bezzi, hairs on pteropleuron are largely blackish. 


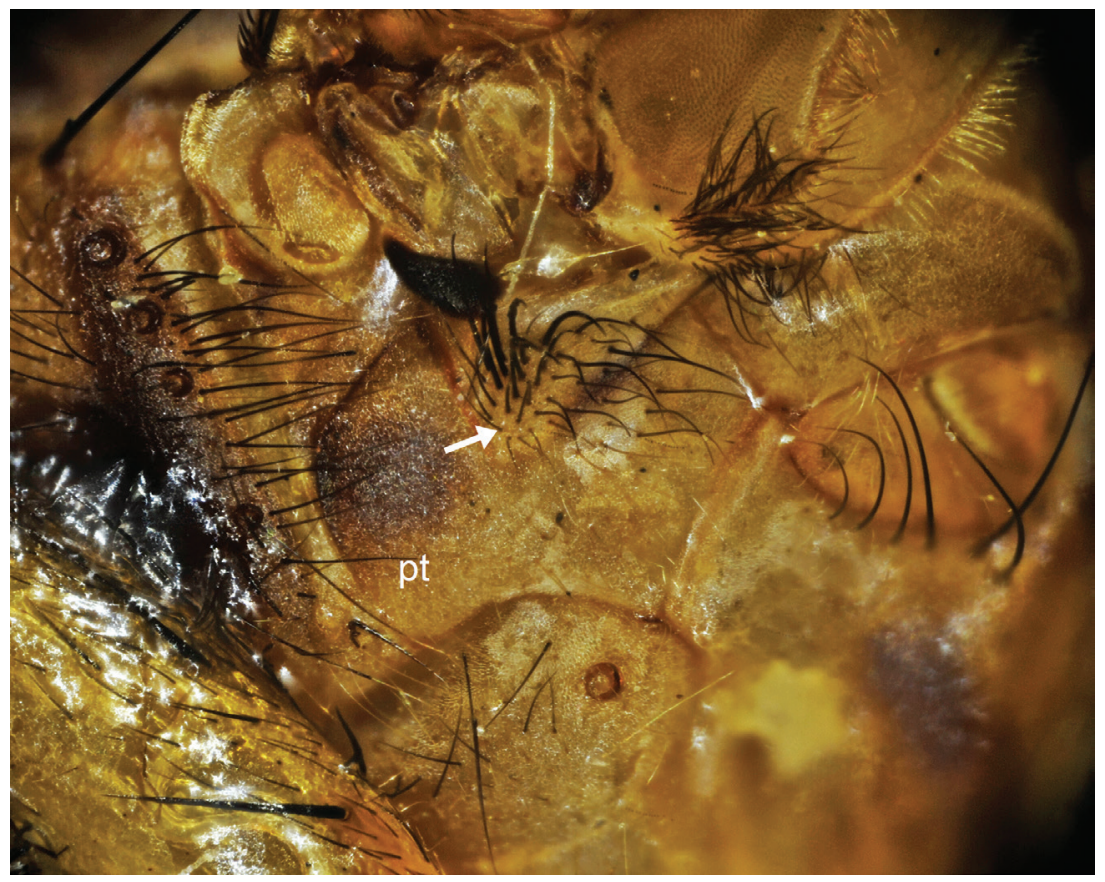

Figure 4. Pteropleuron (pt) of Bengalia fuscipennis Bezzi, which is largely covered with yellow hairs except for a tuft of blackish hairs. Arrow shows the blackish hair tuft.

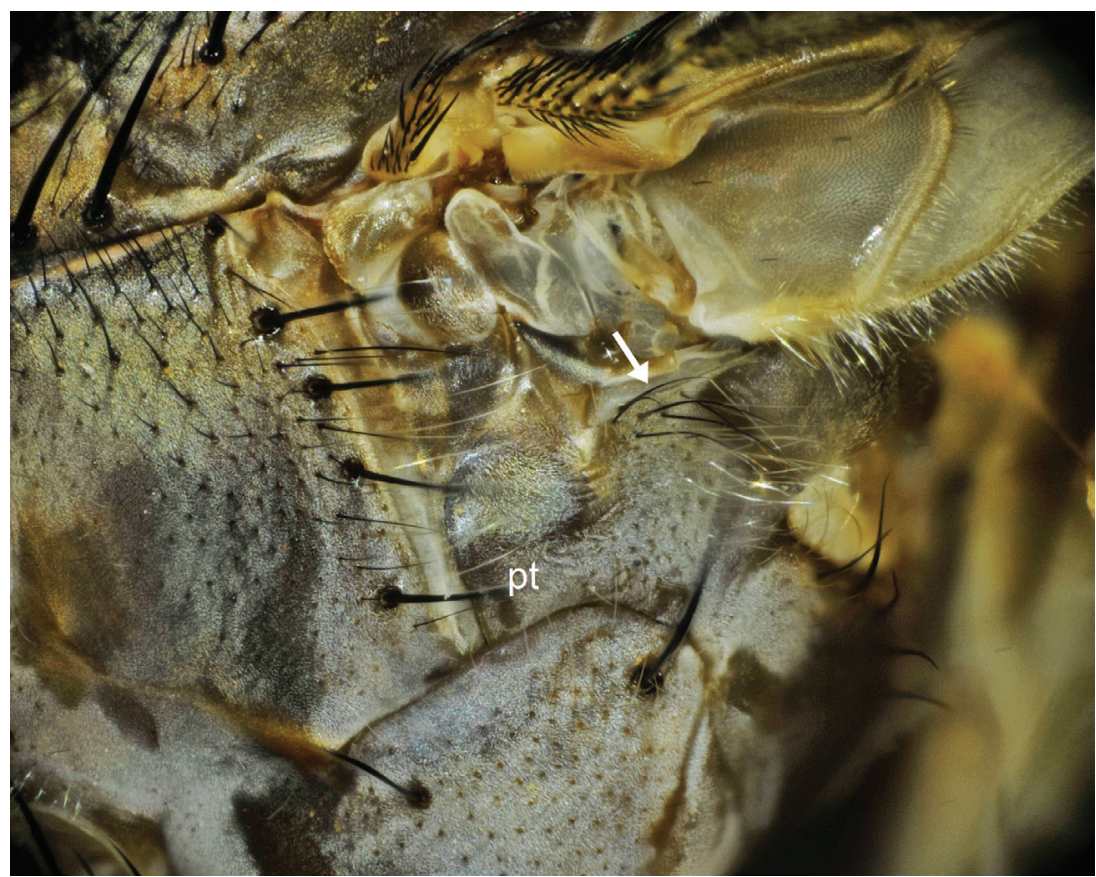

Figure 5. Pteropleuron (pt) of Bengalia varicolor (Fabricius), which is mostly clothed in yellow hairs, with a few black hairs present on upper part. Arrow shows the blackish hairs. 


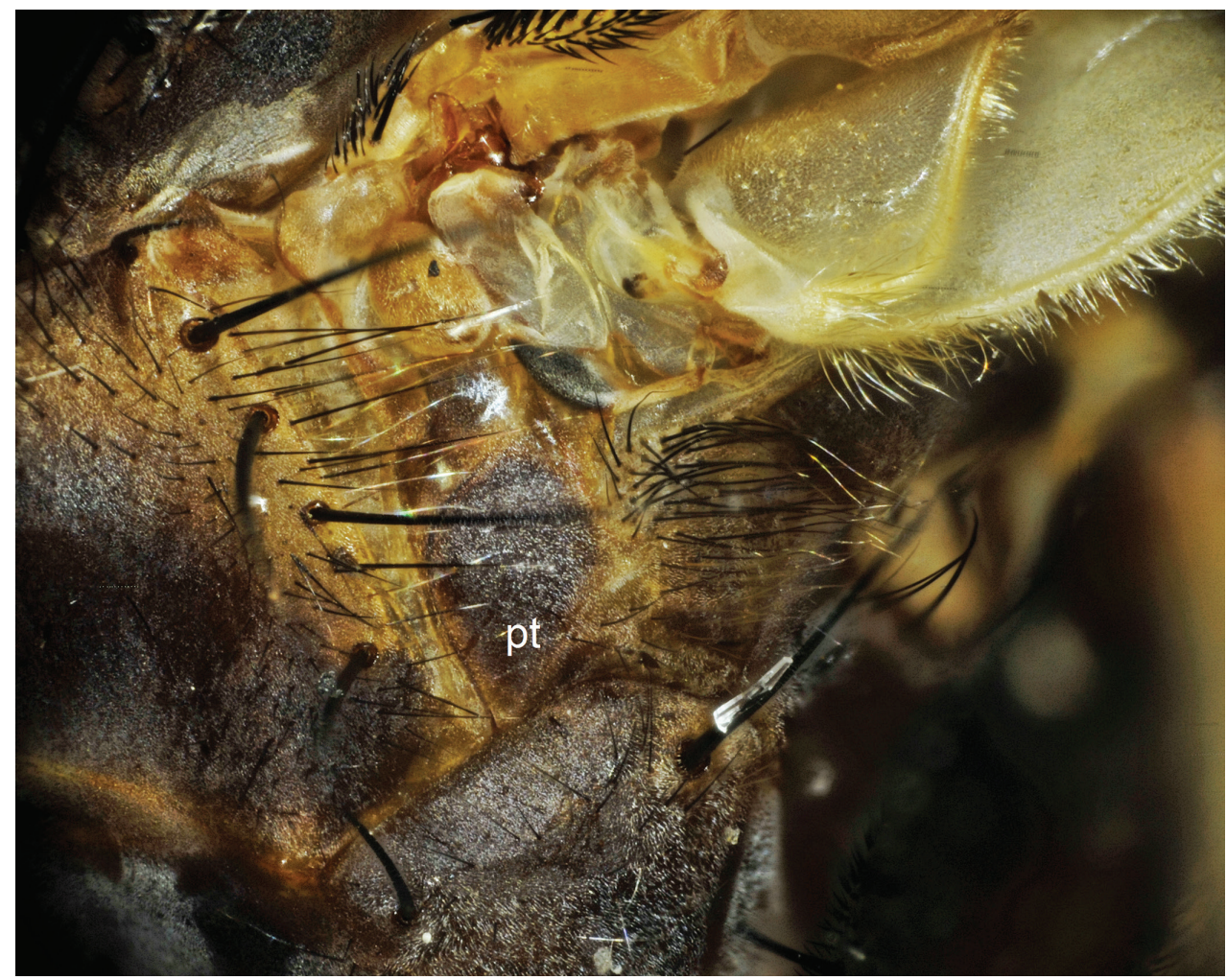

Figure 6. Pteropleuron (pt) of Bengalia emarginata Malloch, which is mostly clothed in black hairs.

\section{Subfamily PHUMOSIINAE}

\section{Key to the species of Caiusa $\dagger$}

1 Mesonotum with fuscous median stripe or spots; male cercus much shorter than surstylus................................................................................... sp. $\ddagger$

- Mesonotum largely fuscous black; male cercus as long as surstylus.................

\section{C. indica Surcouf}

$\dagger$ Species C. testacea Senior-White is excluded from this key, since the morphological characters that used to recognize $C$. testacea (e.g., mesonotum all pale testaceous yellow) is not autapomorphies of this species (Rognes, personal communication), and we did not have Taiwanese $C$. testacea specimens to examine for building a new couplet.

\# The taxonomic status of this species is not clear at present. Its external morphology is similar to that of C. coomani Séguy (Rognes 2011b), while the hypopygium and genitalia are quite different. It might be an undescribed species or only a variation in C. testacea Senior-White (Rognes, personal communication). 


\section{Subfamily POLLENIINAE}

\section{Key to the genera of POLLENIINAE}

1 Parafacial hairy; body mainly black

Pollenia Robineau-Desvoidy [not recorded from Taiwan]

- Parafacial bare; body entirely or largely testaceous yellow, rarely entirely black

Dexopollenia Townsend

Key to the species of Dexopollenia

1 Presutural ac absent D. luteola Villeneuve

- Presutural ac present 2

2 Thorax yellow to dark brown; abdomen entirely yellow, sometimes with black spots on $\mathrm{T}_{4}$ and $\mathrm{T}_{5}$; leg almost entirely yellow except for fuscous tarsus; $\mathrm{AS}_{3}$ largely yellow D. flava (Aldrich)

- $\quad$ Thorax entirely black; abdomen with blackish median stripe; male femora and tibia entirely fuscous black, and entirely orange in female; $\mathrm{AS}_{3}$ entirely brown

D. maculata Villeneuve

\section{Subfamily CHRYSOMYINAE}

Key to the tribes of CHRYSOMYINAE

1 Prealar knob with erect hairs

..Tribe Chrysomyini

- $\quad$ Prealar knob without erect hairs ... Tribe Phormiini, Protocalliphora Hough

\section{Key to the genera of Chrysomyini}

1 Sternopleural bristle $(s t) 0+1$; head dichoptic in both sexes

Ceylonomyia Fan, C. nigripes (Aubertin)

- $\quad$ Sternopleural bristles 1+1; head holoptic to dichoptic in male, dichoptic in female

2 Outer vertical bristle (ov) developed in both sexes; no proclinate ors developed in female (ors $0+1$ ); $\mathrm{T}_{5}$ in female with cleft on median part of posterior margin [larvae facultative predacious species, body with fleshy tubercles]....... Achoetandrus Bezzi

- Outer vertical bristle absent in male, developed in female; 2 proclinate ors (ors $2+1$ ) developed in female; $\mathrm{T}_{5}$ in female without median cleft, truncate posteriorly 


\section{Key to the species of Achoetandrus}

1 Mesothoracic spiracle white or yellow; femora normal in both sexes; head holoptic in male, dichoptic in female; facial ridge not remarkably high; T5 with some pale hairs laterally among black ones.....A. rufifacies (Macquart)

- $\quad$ Mesothoracic spiracle fuscous black to dark brown; femora swollen in both sexes, more noticeably so in male; head dichoptic in both sexes; facial ridge well developed, high

A. villeneuvi (Patton)

\section{Key to the species of Chrysomya}

1 Gena and postgenal area entirely orange-yellow, clothed with pale yellow hairs, except immediately around vibrissa ...................................................2

- Gena and postgenal area entirely fuscous or somewhat rufous anteriorly, entirely clothed in black hairs or with some pale hairs posteriorly...... C. pinguis (Walker)

2 Alar and thoracic squama entirely white except for yellowing of fringe; mesothoracic spiracle small, not longer than length of $\mathrm{AS}_{3}$; upper eye facets not conspicuously larger than lower in male; parafrontal not obliterated in male; eyes separated by slightly less than width of $\mathrm{AS}_{3}$ in male [myiasis-producing species rarely found except by rearing from hosts]....C. bezziana Villeneuve

- $\quad$ At least thoracic squama distinctly infuscated posteriorly; mesothoracic spiracle large, much longer and broader than $\mathrm{AS}_{3}$ in profile; male with upper eye facets conspicuously enlarged and with sharp transition to small facets in lower 1/3; parafrontal almost obliterated and eyes virtually touching above in male [common synanthropic species].

C. megacephala (Fabricius)

\section{Subfamily RHINIINAE}

\section{Key to the tribes and genera of RHINIINAE}

$1 \quad$ Arista pectinate; $a c$ and $d c$ not distinguishable from general vestiture, prescutellar bristles at most weakly developed; suprasquamal ridge bare

.Tribe Rhiniini, 2

- $\quad$ Arista pubescent or plumose, not pectinate Tribe Cosminini, 5

2 Outer $p h$ absent; cell $\mathrm{R}_{5}$ petiolate; male head holoptic, female dichoptic; body metallic green or dark blue ... Chlororhinia Townsend [not recorded from Taiwan]

- $\quad$ Outer $p h$ present; cell $\mathrm{R}_{5}$ variable; male head variable, female dichoptic; body variable in color.

3 Hind tibia without conspicuous row of $a d$, but with 2-3 ad as long as or longer than tibial diameter; cell $\mathrm{R}_{5}$ open; body slender, parallel-sided; abdomen mostly testaceous 
- $\quad$ Hind tibia with conspicuous row of subequal setae on anterodorsal surface, longer than general vestiture, sometimes 2-3 rather strong ad developed among them; fore tibia with $1 p v$; body rather stout with ovate abdomen, usually of dark coloration. Cell $\mathrm{R}_{5}$ petiolate; stenopleuron brassy, without pollinosity; mesopleuron without setigerous spots; legs entirely yellow.... Rhinia Robineau-Desvoidy Cell $\mathrm{R}_{5}$ open at wing margin or closed; if petiolate then sternopleuron heavily dusted. Stomorbina Rondani Arista plumose, rays at least as long as width of $\mathrm{AS}_{3}$ in anterior view; fore tibia without or with 1 posterior bristle $(p)$ Arista pubescent, longest hairs never exceeding 1.5 times width of $\mathrm{AS}_{3}$ in anterior view; fore tibia with $1 p$ Rhyncomya Robineau-Desvoidy

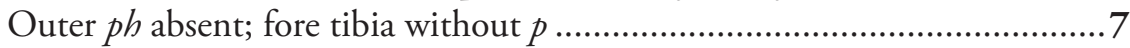

Outer $p h$ present; fore tibia with $1 p$, rarely lack in Malayomyza .................8 8 Prostigmatal bristles ( $p s t)$ absent; two longitudinal silver white stripes present on dorsum Borbororbinia Townsend, B. bivittata (Walker) Prostigmatal bristles present; yellowish brown dorsum with or without three fuscous longitudinal stripes, or fuscous dorsum with two longitudinal silver white to grey stripes Sumatria Malloch Presutural $a c$ absent or indistinct; $d c$ and postsutural $a c$ usually indistinct except for prescutellars; if 1-2 postsutural ac developed as prescutellars, then propleuron hairy.

Cosmina Robineau-Desvoidy [not recorded from Taiwan]

Presutural $a c$ well developed at least in one pair; $d c$ also well developed; propleuron bare...

Fore tibia without $p$; small fly, less than $4 \mathrm{~mm}$ in length, blackish and shiny, with bronzy tinge; humerus, propleuron, upper and anterior part of mesopleuron reddish brown; abdomen reddish brown in part on $\mathrm{T}_{1+2}$ and $\mathrm{T}_{3}$; male head dichoptic

Malayomyza Malloch [not recorded from Taiwan]

Fore tibia with $1 p$; medium- to large-sized fly having thorax usually metallic green, blue and purple, more or less pollinose; humerus, propleuron, and mesopleuron concolorous with thoracic dorsum; abdomen concolorous with thoracic dorsum, also pollinose, sometimes tessellated; male head usually holoptic to subholoptic.

10 Mesopleuron with group of bristles on its upper part; bend of vein $M_{1+2}$ regularly curved or angulose; male hypopygium of normal size, scarcely visible on abdomen in profile; female last sternite not projecting posteriorly ..... Isomyia Walker

- $\quad$ Mesopleuron without bristle on its upper part next to first notopleural bristle; bend of vein $\mathrm{M}_{1+2}$ gently curved; male hypopygium and $\mathrm{ST}_{5}$ very strongly developed, altogether almost same size as rest of abdomen; female last sternite widely uncovered by corresponding tergites, its posterior border projecting outwards 


\section{Tribe Rhiniini}

\section{Key to the species of Stomorbina}

1 Mesopleuron with 1-2 bristles on upper corner of posterior margin ............ 2

- Mesopleuron with complete row of black bristles along posterior margin; wing strongly infuscated along costal border and with distinct apical suffusion; fore tibia blackish .............................................. S. veterana Villeneuve

2 Mesopleuron without distinct piliferous spots........................................... 3

- $\quad$ Mesopleuron with distinct piliferous spots..............................................5

3 Sternopleuron as densely yellow pollinose as mesopleuron ..........................4

- $\quad$ Sternopleuron and hypopleuron glossy black, not pollinose; cell $\mathrm{R}_{5}$ open; abdomen blackish, with violet tinge

S. melastoma (Wiedemann) [not recorded from Taiwan]

4 Thoracic squama with lobulate inner border; cell $\mathrm{R}_{5}$ closed, petiolate

..S. xanthogaster (Wiedemann)

- $\quad$ Thoracic squama without lobulate inner border; cell $\mathrm{R}_{5}$ open

$5 \quad$ Hind femur yellowish at base; cell $\mathrm{R}_{5}$ open narrowly; anterior lower part of mesopleura and anterior part of sternopleuron glossy, black; male abdomen not pollinose, without piliferous spots; $\mathrm{T}_{1+2}$ with only narrow fuscous posterior marginal band, without median stripe

S. discolor (Fabricius)

- $\quad$ Hind femur entirely dark brown; cell $\mathrm{R}_{5}$ open; anterior lower part of mesopleuron and anterior part of sternopleuron black, weakly gray pollinose, not glossy; male abdomen with piliferous spots; $\mathrm{T}_{1+2}$ with both fuscous anterior and posterior marginal band, with median stripe

S. obsoleta (Wiedemann)

\section{Key to the species of Idiella}

1 Basicosta black; occipital dilatation, mesopleuron and sternopleuron with distinct piliferous spots ....................................................................... 2

- Basicosta brown; occipital dilatation, mesopleuron and sternopleuron without distinct piliferous spots

2 First visible tergite without lateral bristle among fine yellow general vestiture; hind tibia in male with fine long hairs on posteroventral surface, length of hairs more than tibial diameter I. divisa (Walker)

- $\quad$ First visible tergite with 1 to several black lateral bristles among fine yellow general vestiture; hind tibia in male without fine long hairs on posteroventral surface, tibial hairs not exceeding tibial diameter. I. euidielloides Senior-White

3 Second antennal segment reddish; mid tibia with $2 p$ and brush of hairs in male; male frons usually broader than width of ocellar triangle..... 
- $\quad$ Second antennal segment fuscous; mid tibia with $1 p$, but without brush of hairs on inner surface of apex in male; male frons variable in width

I. tripartita (Bigot) [not recorded from Taiwan]

\section{Tribe Cosminini}

\section{Key to the species of Isomyia}

1 Thoracic squama strongly lobulate; body very stout 2

- Thoracic squama generally not lobulated, not reaching base of scutellum, its longitudinal diameter longer than transverse; body usually slender; antenna yellow; ac 2+4; alar and thoracic squama yellowish white. I. tibialis (Villeneuve) Mesopleural hairs and hairs of other pleural areas as well, soft and yellow to golden, except for usual black setulae just below notopleural suture; mesothoracic spiracle yellow . .3

- $\quad$ Mesopleural hairs more extensively black than indicated above, with some soft black hairs on mesopleuron, sometimes remote from notopleural suture, and on sternopleuron............................................................................. 4

3 Basicosta bright yellow; epaulet yellowish; pleura and abdomen densely pollinose in male, less so in female, but dorsum of $\mathrm{T}_{5}$, when viewed laterally at angle, with tessellated pattern of pollinosity; black lateral bristles on $\mathrm{T}_{1+2}$ surrounded, at least on three sides, by pale yellow hairs

I. viridaurea (Wiedemann)

- $\quad$ Basicosta black; epaulet black; $\mathrm{T}_{3}$ and $\mathrm{T}_{4}$ without marginal band; wing hyaline, sometimes slightly infuscated apically in female; parafrontal in female subequal to frontal stripe at middle of frons; hind tibia without $a v$ in male ..

.I. electa (Villeneuve)

Marginal scutellar bristles (msc) 4, the last three spaced at closer intervals than basal bristle; both alar and thoracic squama pale yellow; posterior mesopleural fringe yellow; some hairs on notopleuron, lower part of mesopleuron, and part of sternopleuron yellow to yellowish brown I. pseudolucilia (Malloch) Marginal scutellar bristles 3, spaced at approximately equal intervals .5 Pleura with extensive yellow hairs, at least around $p s t$ and propleural bristles $(p p)$ and on part of sternopleuron; posterior mesopleural fringe golden ......6 Pleural hairs entirely black or virtually so; posterior mesopleural fringe brown to black; alar and thoracic squama wholly dark brown to black.

I. oestracea (Séguy)

Mesothoracic spiracle entirely bright yellow to golden; $\mathrm{T}_{3}$ and $\mathrm{T}_{4}$ without marginal band; wing hyaline, sometimes slightly infuscated apically in female; parafrontal in female subequal to frontal stripe at middle of frons; hind tibia without $a v$ in male.

I. electa (Villeneuve) 


\section{Key to the species of Rhinia}

1 Mesopleura, and usually occipital dilatation too, with distinct piliferous spots; sternopleura pruinose; cell $\mathrm{R}_{5}$ open R. sauteri Peris

- Mesopleura without distinct piliferous spots; male scutellum with long and fine hair; interfrontalia width twice each parafrontal in female.

R. apicalis (Wiedemann)

\section{Key to the species of Rhyncomya}

1 Propleuron hairy; $\mathrm{T}_{3}$ and $\mathrm{T}_{4}$ with black median stripe; $\mathrm{T}_{4}$ with dark marginal band; $\mathrm{T}_{5}$ blackish ............................................... . notata (van Der Wulp)

- $\quad$ Propleuron bare; antenna yellowish fuscous, $\mathrm{AS}_{3}$ brownish; posterior mesopleural bristles 6-7; hind tibia with 2 fine $a v$. Female frons as wide as 0.67 eye wide; interfrontal area reddish brown, not wider at lunule; femur entirely black

$R$. setipyga Villeneuve

\section{Key to the species of Strongyloneura}

1 Male sternite without brush-like tuft of hairs or bristles except ST; ; anteroventral side of hind coxa with yellow fine hairs and black hairs....S. prasina Bigot

- $\quad$ Male with brush-like tuft of hairs or bristles on each sternite .......................2

2 Third sternite with large brush-like tuft of hair ...... S. diploura Fang \& Fan

- $\quad$ Third sternite without tuft of hair; $\mathrm{ST}_{4}$ with tuft of hair... S. prolata (Walker)

\section{Key to the species of Sumatria}

1 Dorsum of thorax orange, with paired narrow longitudinal brownish stripes separated by a median silvery gray-dusted area ............. S. flava (Villeneuve)

- $\quad$ Dorsum of thorax testaceous, with three dark longitudinal stripes ..............2

2 Dorsum of thorax with three dark longitudinal stripes separated by silvery gray-dusted areas.................................. c. chiekoae Kurahashi \& Tumrasvin

- $\quad$ Dorsum of thorax with three dark longitudinal stripes, without gray pruinosity... S. vittata (Peris) 


\section{New taxon}

\section{Paradichosia lui sp. n.}

http://zoobank.org/23029B64-E9A8-4A44-B292-E88E08201588

Figs 7, 9

Description. Male. Head: Holoptic, eyes hairy; frons index $<0.01$; frontal stripe dark brown to black, obliterated at narrowest point of frons; parafrontal dark brown to black, silver pollinose, setulose, with about 7 pairs of orbital bristles (ori); parafacial dark brown to black, silver pollinose, setulose, about as wide as width of AS3; face dark brown to fuscous, slightly gray pollinose, facial carina not developed; facialia dark brown to fuscous, gray pollinose, with several hairs above vibrissa; mediana dark brown, slightly pollinose, with some hairs below; vibrissaria brown, with several bristles; vibrissa developed; epistome yellowish, slightly projecting forward, not obviously demarcated from face; gena blackish, gray pollinose, clothed with black hairs; postgena concolorous with gena, not demarcated from gena, with mostly black hairs but yellowish hairs posteriorly; occiput concolorous with gena, whitish gray-dusted, clothed in yellowish soft hairs at inner part and black hairs along outer margin, epicephalon and upper parts along posterior eye margins black, slightly dusted; $\mathrm{AS}_{2}$ fuscous, reddish to brown, at joint of $\mathrm{AS}_{3}$ pale apically; $\mathrm{AS}_{3}$ fuscous, somewhat reddish to brown at joint of $\mathrm{AS}_{2}$, yellowish white pollinose, about 3 times as long as $\mathrm{AS}_{2}$; arista dark brown, long plumose on basal 2/3; palpus orange, with black setulae.

Thorax: blackish, thinly whitish gray pollinose on dorsum and pleura; humerus, postalar callus and scutellum concolorous with thoracic dorsum; prosternum black, with brown hairs below; propleuron yellowish to blackish, whitish pollinose posteriorly, with yellowish brown hairs; mesopleuron and sternopleuron clothed with black hairs and bristles; supraspiracular convexity pubescent, without long upstanding hairs; hypopleuron clothed in black hairs and bristles; other pleural hairs also blackish; mesothoracic spiracle blackish brown on upper part, lower part brown; metathoracic spiracle fuscous; postalar declivity fuscous black, with black hairs; tympanic tuft present; anterior parasquamal tuft present.

Chaetotaxy: ac 2+3; $d c 2+3$; ia 1+2; humeral bristles (b) 3; ph 2-3, 2 strong, 1 fine bristle present in front of strong inner ph; prs 1; supraalar bristles (sa) 3; postalar bristles $(p a)$ 3; st 2+1; msc 5; discal scutellar bristle $(d s c) 1$; notopleural bristles $(n) 2$; propleural bristles $(p p)$ more than 5 ; pst 1 .

Wings: Brownish hyaline; veins brown; epaulet black, with black setulae and bristles; basicosta blackish; subcostal sclerite dark brown, yellowish pubescent; node of 2nd $\left(\mathrm{R}_{2+3}\right)$ and 3rd $\left(\mathrm{R}_{4+5}\right)$ longitudinal veins with a few black setulae above and below; 4th longitudinal vein $\left(\mathrm{M}_{1+2}\right)$ forming right angle; cell $\mathrm{R}_{5}$ open in wing margin; section of 4th vein from bend to wing margin slightly curved inward; alar squama fuscous, paler at base with golden brown pubescence, semitransparent on apical part, with tuft of dark brown hairs at inner lower margin; thoracic one fuscous, lobulate bare on dorsal surface. Halter brownish, with yellowish apex. 


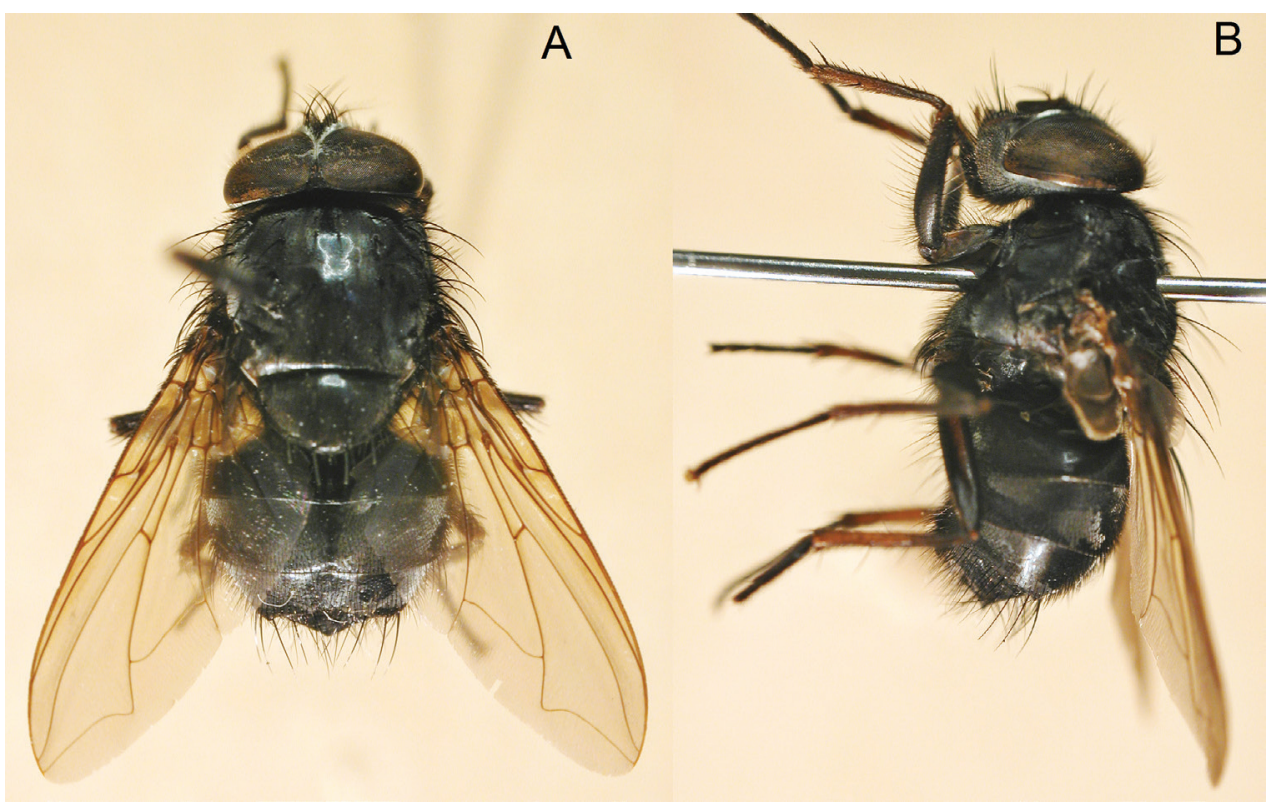

Figure 7. Paradichosia lui sp. n., Ô. A dorsal view B lateral view.

Legs: Femora dark brown to black, tibia brownish, tarsi blackish; fore coxa dark brown to black, more or less whitish grey pollinose; mid and hind coxae brownish black, more or less whitish grey pollinose; fore tibia with $1 p$ and row of several short $a d$; mid tibia with $1 a d, 1 p, 2 p v$, and $1 v$; hind tibia with $3 a d, 2-3 p d$, and 2-3av.

Abdomen: Blackish, submetallic, with bronze tinge, slightly whitish grey pollinose, fine black median stripe more or less distinct on $\mathrm{T}_{3}$; hairs and bristles black; $\mathrm{T}_{1+2}$ with 2-4 lateral marginal bristles; $\mathrm{T}_{3}$ with lateral and median $m b$; $\mathrm{T}_{4}$ with row of $m b$; $\mathrm{T}_{5}$ with row of $m b$ and several discal bristles; $\mathrm{ST}_{2}$ large, elongated, blackish, whitish gray pollinose except for margin, clothed in black hairs only; $\mathrm{ST}_{3}$ and $\mathrm{ST}_{4}$ with tuft of short hair as shown in Fig. 9G, H. ST 5 with lobes narrower and bended inward at tip as shown in Fig. 9C.

Hypopygium small in size, withdrawn from sight; genitalia as shown in Fig. 9A, B, $\mathrm{D}, \mathrm{E}, \mathrm{F}$, aedeagus with fine and slender paraphallus and acrophallus.

Female. Unknown.

Length: $9.5 \mathrm{~mm}$

Holotype $\widehat{\lambda}$, TAIWAN, Yilan, Datong Township, Jiuliao River, $c a .158$ m, river-

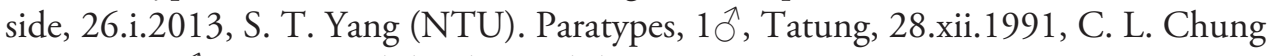
(NSMT); 10, Tatung, Chilanshan, Chihtuan, 15.xi.1961, J. C. Lien (NSMT).

Etymology. The specific epithet lui is named after Mr. I-Tse Lu, who guided the first author to the collecting site and helped collect specimens.

Type depository. Holotype $\left(\delta^{\lambda}\right)$ is deposited in the Insect Museum of National Taiwan University (NTU); two paratypes (type series NSMT-I-Dip6958, 6959) are deposited in the National Museum of Nature and Science, Tokyo (NSMT). 
Diagnosis. This new species, which has hairy eyes and a blackish scutellum, is similar to P. dubia (Malloch) from Java, Indonesia in general morphology. Nevertheless, it can be easily distinguished from $P$. dubia by having very short hairs on the tuft of $\mathrm{ST}_{3}$ in the male.

Bionomics. Adults were found on the bush near the stream side.

Distribution. Taiwan (Yilan).

\section{New Record from Taiwan}

\section{Silbomyia hoeneana Enderlein}

Figs 8,10

Redescription. Male. Head: Eyes dichoptic; frons index 0.42 ; frontal stripe yellow to yellowish-orange, very wide, about 4 times as wide as a parafrontal, black setulose on outer part; parafrontal yellow, silvery-yellow pollinose, with about 9 pairs of ori, reclinate ors 1 , proclinate ors 2 ; parafacial yellow, silvery-yellow pollinose, bare, about 2 times as wide as width of $\mathrm{AS}_{3}$; face yellow, slightly yellowish pollinose; facial carina developed, rather short and broad, shorter than distance from lunule to median ocellus, more or less ridge-like, not fusiform, facialia yellow, slightly yellowish pollinose, with several black hairs above vibrissa; mediana yellow, silvery-yellow pollinose; vibrissaria yellow, with several strong bristles; vibrissa well developed; epistome yellow, not obviously demarcated from face; gena yellow, silvery-yellow pollinose, covered with yellowish-fuscous to brown hairs; peristomal bristles black and stout; postgena concolorous with gena, not demarcated from gena, with yellowish hairs; postorbits dark brown, bright silver pollinose; upper occiput dark brown to black, slightly silvery-gray pollinose, with black hairs, lower occiput yellow, silvery-yellow pollinose, with golden-yellow hairs; upper epicephalon yellow, concolorous with frontal stripe, lower part brown; $\mathrm{AS}_{2}$ yellowish to pale orange; $\mathrm{AS}_{3}$ yellowish to pale orange, yellowish white pollinose, about 3 times as long as $\mathrm{AS}_{2}$; arista fuscous brown, almost entirely long plumose; palpus pale orange, with black setulae.

Thorax: Metallic bluish-green to blue, with somewhat purplish tinge, slightly silvery-gray pollinose on dorsum and pleura; humerus, postalar callus, and scutellum concolorous with thoracic dorsum; outer prosternum yellowish, inner part dark brown, with rather long black hairs; propleuron dark brown, silvery-gray pollinose, with metallic greenish tinge, covered with brown hairs; supraspiracular convexity brownish pubescent, without long upstanding hairs; hypopleural with row of long black bristles; other pleural hairs black; mesothoracic spiracle dark brown; metathoracic spiracle dark brown; postalar declivity fuscous black, with black hairs; tympanic tuft absent; anterior parasquamal tuft absent.

Chaetotaxy: $a c 3+4-5$; $d c 3+4$; ia $1+2-4$, sometimes 2 weaker postsutural $i a$ present; $h$ 4-5; ph 3; prs 1 ; prealar 1 ; sa 2; pa 2; st 2+1; msc 3-4; dsc 2-4; $n 2$; pp 2; pst 1-3.

Wings: Dark brown infuscate, most strongly brown along veins, paler in cells and to hind margin; veins dark brown; epaulet black, with black setulae and bristles; basi- 


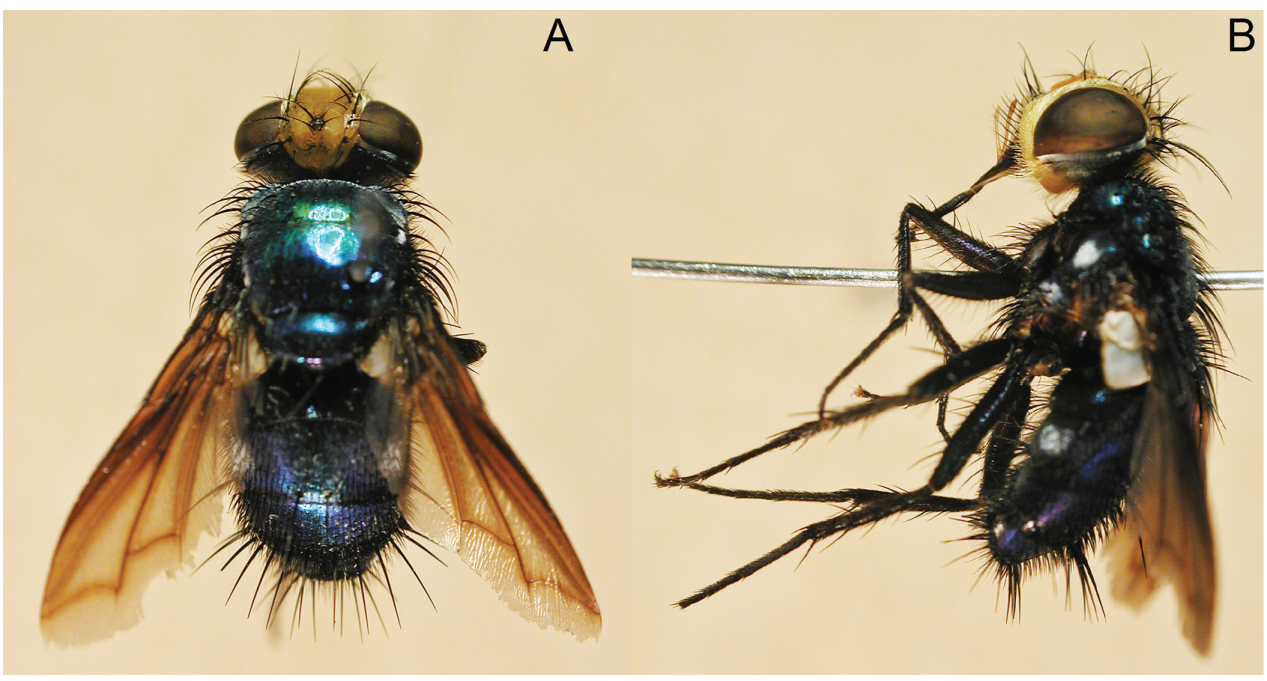

Figure 8. Silbomyia hoeneana Enderlein, ठ̊. A dorsal view B lateral view.

costa black, with brown pubescence; subcostal sclerite dark brown; node of $\mathrm{R}_{2+3}$ and $R_{4+5}$ veins with several black setulae extending to $R_{4+5}$ above and below; vein $M_{1+2}$ forming right angle; Cell $\mathrm{R}_{5}$ open at wing margin; section of vein $\mathrm{M}_{1+2}$ from bend to wing margin slightly curved inward; alar squama whitish, with pale yellow edge and white fringe; thoracic squama whitish, bare on dorsal surface, with dark brown edge and dark brown fringe. Halter fuscous, darkened on apex.

Legs: Femora dark brown to blackish, with metallic violet tinge; tibiae brown; tarsi dark brown; coxa dark brown to blackish, covered with black hairs and bristles anteriorly; fore tibia with row of several strong $a d, 3$ short $p d, 2-3$ strong $p$; mid tibia with row of several strong $a d$, several short $p d, 2-3$ strong $p, 1$ strong $a v$; hind tibia with 2 $a v$, row of several strong $a d, 4$ long $p d$.

Abdomen: Metallic bluish-green to blue, with somewhat purplish tinge, slightly silvery-gray pollinose; hairs and bristles black; $\mathrm{T}_{1+2}$ with 1 lateral marginal bristle; $\mathrm{T}_{3}$ with lateral and 1 pair of strong median $m b$, sometimes with 1 or a pair of median discal bristles weakly developed; $\mathrm{T}_{4}-\mathrm{T}_{5}$ with row of $m b$; sternites dark brown with metallic violet tinge, covered with black bristles and hairs. Fifth sternite with long and wide lobes, longer than basal part, as shown in Fig. 10C.

Hypopygium not prominent; genitalia as shown in Fig. 10A, B, D, E, F, paraphallus stout, strongly ossified; hypophallus and acrophallus stout.

Female. Head: Eyes dichoptic; frons index 0.54; frontal stripe yellow to yellowishorange, broad, about 2.8 times as wide as one parafrontal, black setulose laterally; parafrontal yellow, silvery-yellow pollinose, broader than that of male, with about 9 pairs of ori, reclinate ors 1, proclinate ors 2; parafacial yellow, silvery-yellow pollinose, bare, broader than that of male, about 3 times as broad as width of $\mathrm{AS}_{3}$; ors $2+1$; ocellar bristle (oc) 1; postocellar bristles (pooc) 3-4; ov 1; inner vertical bristle (iv) 1; postoccipital bristle $(p o c) 1$; occipital bristle $(o c c) 1$. 

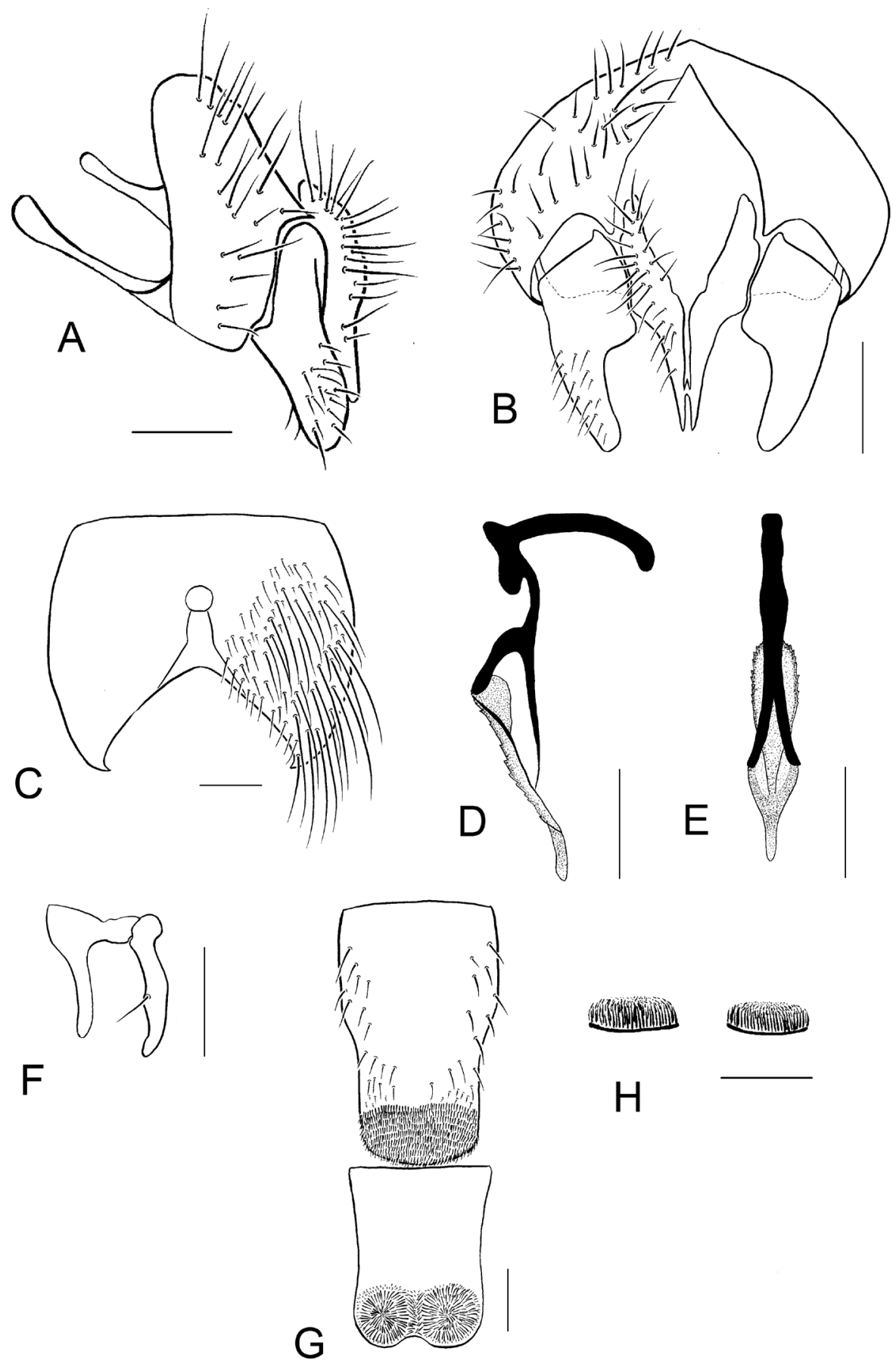

Figure 9. Sternites and genitalia of Paradichosia lui sp. n., O. A Epandrium, cercus, and surstylus, lateral view B Cercus and surstylus, caudal view C Fifth abdominal sternite, ventral view D Aedeagus, lateral view E Aedeagus, posterior view $\mathbf{F}$ Anterior and posterior parameres $\mathbf{G}$ Third and fourth abdominal sternites, ventral view $\mathbf{H}$ Tufts on the third (left) and fourth (right) abdominal sternites. Scale bars: $0.2 \mathrm{~mm}$. 

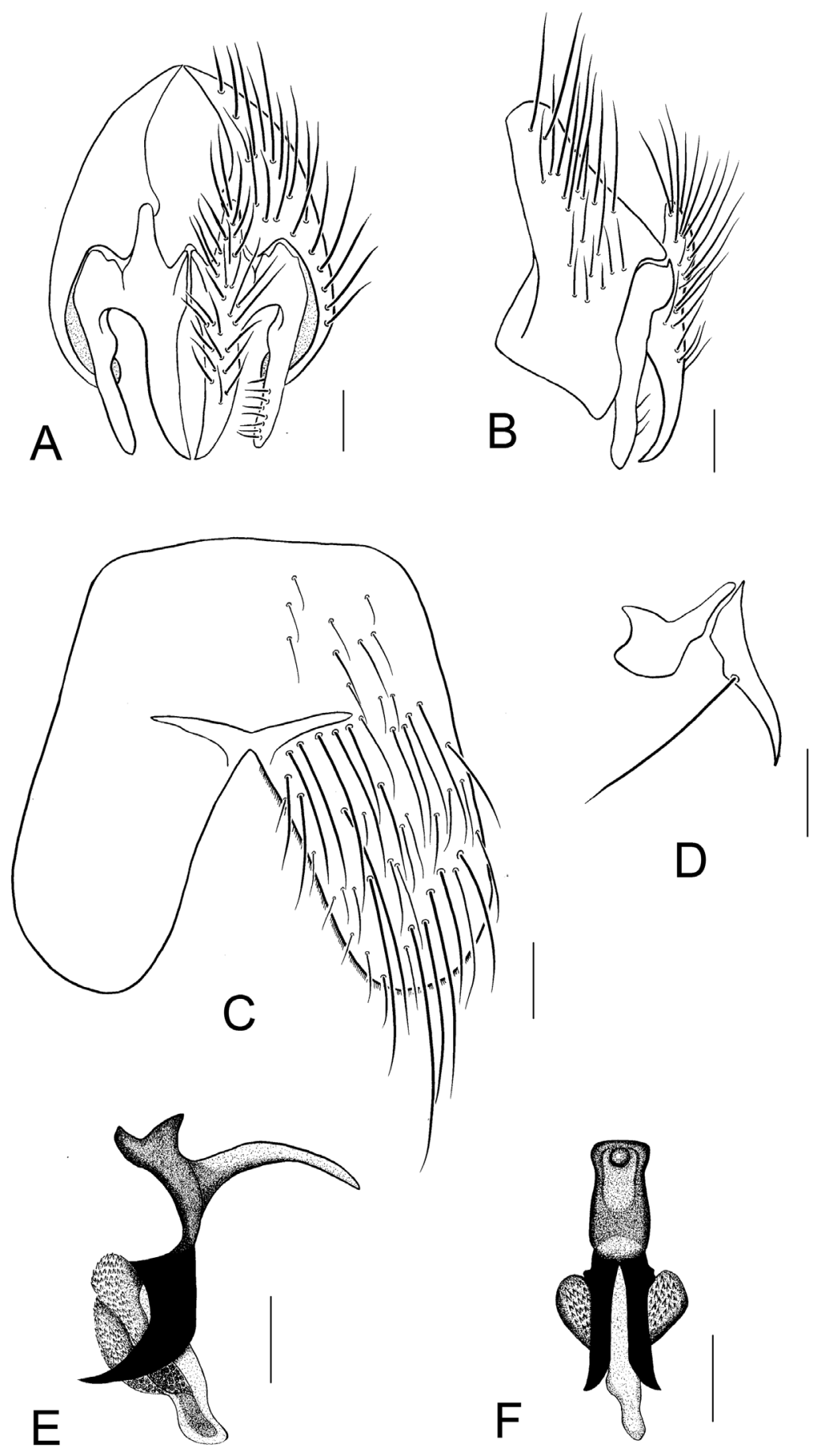

Figure 10. Sternite and genitalia of Silbomyia hoeneana Enderlein, ô. A Cercus, and surstylus, caudal view B Epandrium, cercus, and surstylus, lateral view $\mathbf{C}$ Fifth abdominal sternite, ventral view $\mathbf{D}$ Anterior and posterior parameres $\mathbf{E}$ Aedeagus, lateral view $\mathbf{F}$ Aedeagus, posterior view. Scale bars: $0.2 \mathrm{~mm}$. 

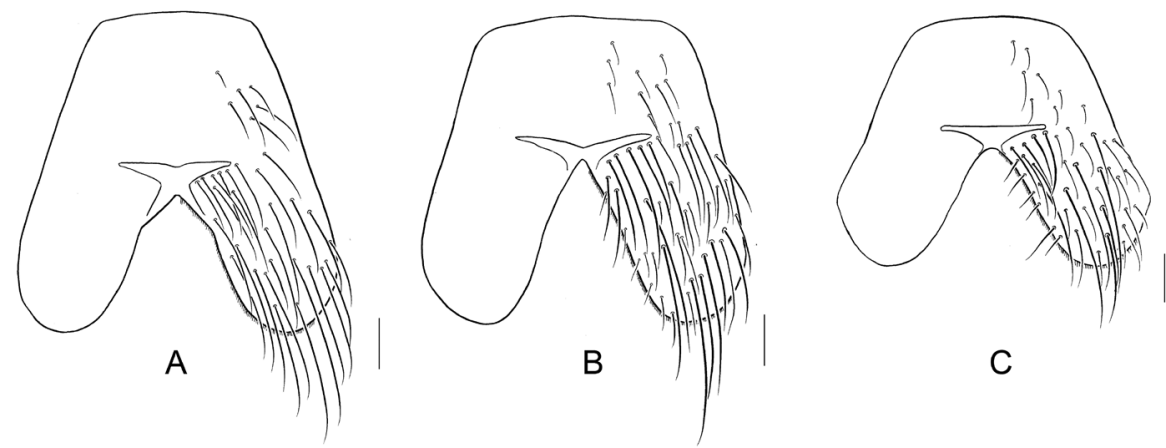

C

Figure II. The male fifth abdominal sternites of Silbomyia species. A S. sauteri B S. hoeneana, Taiwan C $S$. hoeneana, China. Scale bars: $0.2 \mathrm{~mm}$.

Legs: Fore tibia with row of several strong $a d, 4 p d, 2$ strong $p$; mid tibia with row of several strong $a d, 3 p d, 2$ strong $p, 1$ strong $a v$; hind tibia with $2 a v$, row of several strong $a d$, 4 long $p d$. Otherwise same as for male.

Length: $12.0-17.0 \mathrm{~mm}$.

Diagnosis. The specimens of this species collected in Taiwan are slightly different in external morphology from those collected in China. Taiwanese specimens are more bluish when compared to the greener Chinese individuals, and the shape of the $\mathrm{ST}_{5}$ is different (Fig. 11) (A, S. sauteri; B, S. hoeneana, collected in Taiwan; C, S. hoeneana, collected in China), the lobes of the $\mathrm{ST}_{5}$ of $S$. hoeneana collected in Taiwan are longer than the basal part, while those of $S$. hoeneana collected in China are almost equal to the basal part.

Bionomics. Adults are frequent flower visitors.

Distribution. Taiwan and Southern China (Jiangsu Province, Zhejiang Province, Sichuan Province, Jiangxi Province, Hainan Province, Guangdong Province, Yunnan Province).

\section{Checklist}

The following list of Taiwanese Calliphoridae is based mainly on the specimens examined and to a lesser extent on the published records. Names of the collecting localities are based on the original spelling on the collecting labels of specimens.

\section{Subfamily AMENIINAE}

\section{Tribe Ameniini}

Silbomyia Macquart, 1843

Silbomyia cyanea (Matsumura, 1916)

Materials. $1 \widehat{ }{ }^{\Uparrow}$, Kaohsiung City, Liugui Dist., Tsaidie Valley, 366 m, secondary forest, 31.iii.2013, S. T. Yang (NTU); 1, P'ing-tung Hsian, K'en-ting-kung-yuan, 
2.iv.1965, R. Kano (NSMT); 10^, P'ing-tung Hsien, Kuei-chiao-liu, 3.iv.1965, S. Ueno (NSMT); 29, T'ai-nan Hsien, Kuan-tzu-ling, 250 m, 6.iv.1965, Rokuro Kano (NSMT); 19, Chia-I Hsien, Ch'-hsin-liao, 15.iv.1965, S. Ueno (NSMT); 1우, Jiji (Chichi), 30.iv.2006, H. Kurahashi (NSMT); 1운 Kuan-tzu-ling, 250 m, 6.iv.1965, R. Kano (NSMT); 3ㅇ, Puli, 26.ix.1965, K. Kaneko (NSMT); 10ิ, Chihpen, 20.vii.1985, S. Shinonaga (NSMT); 10 , Nanshanchi, 26.vii.1985, S. Shinonaga (NSMT); 1 $\hat{\jmath}$, Kenting Park, 15.vii.1985, S. Shinonaga (NSMT); $2 \hat{\jmath} 1+$, Chihpen hot spring, 3-4.vi.1992, R. Kano and H. M. Lin (NSMT); 10̃, Kenting, 11.x.1965, K. Kaneko (NSMT); 1q, Janai (Mushia), 28.ix.1965, K. Kaneko (NSMT); 10,, Chuchi, 5.x.1965, K. Kaneko (NSMT); 10 19, Shanpin, Kaohsiung Co., 6.iv.1996, R. Matsumoto (NSMT); 3 +, Puli, Nanshanhsi, 23-24.v.1992, R. Kano (NSMT);

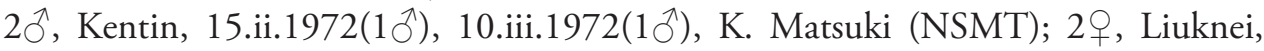
12.vii.1985, S. Shinonaga (NSMT).

\section{Silbomyia sauteri Enderlein, 1936}

Materials. 10ิ, Tainan City, Baihe Dist., Guanziling, Red-Leaf Park, 357 m, secondary forest, 21.iii.2013, S. T. Yang (NTU); 2 , Santimen, 13.vii.1985, S. Shinonaga (NSMT); 2ㅇ, Kentin, 15.ii.1972(1 + ), 10.iii.1972(1 ), K. Matsuki (NSMT); 1ㅇ, Taipei Fushan Botanical Garden, 700 m, 24-26.x.2002, M. Owada (NSMT); 1우, Kuan-tzu-ling, 7.iv.1965, S. Miyamoto (NSMT); 1 9 , Jih-yueh-tan, 24.ix.1965, K. Kaneko (NSMT); 1, Lushan, 1,000 m, 24-25.vii.1985, S. Shinonaga (NSMT); 2ð, Shannpin, Nantou Co., 7.iv.1996, R. Matsumoto (NSMT); 1 ${ }^{\lambda}$, Jiji (Chichi), 30.iv.2006, H. Kurahashi (NSMT); 1 , Fushan B. G., 600 m, 3-6.v.2006, H. Kurahashi (NSMT); 1q, Kuanzuling, 7.x.1965, K. Kaneko (NSMT); 10ึ, Paling, Taoyuen, 9-11.vi.1992, R. Kano (NSMT).

\section{*Silbomyia hoeneana Enderlein, 1936}

Materials. 29, T'ai-nan Hsien, Kuan-tzu-ling, 250 m, 06.iv.1965, Rokuro Kano (NSMT); 10, Taoyuen, Paling, 09-11.vi.1992, R. Kano (NSMT); 1ㅇ, Kentin, 15.ii.1972, K. Matsuki (NSMT).

\section{Tribe Catapicephalini}

Catapicephala Macquart, 1851

Catapicephala dasyophthalma Villeneuve, 1927

Note. See to James (1977: 532). 


\section{Catapicephala ruficornis Villeneuve, 1927}

Materials. 1ð̂, Kaohsiung, Shanping, 640 m, 21-30.iv.1988, C. Young, R. Davidson $\&$ J. Rawlins (CMNH); 1우 Kaohsiung, Shanping, 640 m, 1-10.iv.1988, C. Young, R. Davidson \& J. Rawlins (CMNH); 1 + , Chihpen Hot Spring, 3-4.vi.1992, R. Kano (NSMT).

\section{Catapicephala splendens Macquart, 1851}

Note. See to James (1977: 532).

\section{Subfamily CALLIPHORINAE Aldrichina Townsend, 1934}

\section{Aldrichina grabami (Aldrich, 1930)}

Materials. $1 \hat{\jmath} 1$, Nantou County, Ren'ai Township, Songgang, $2049 \mathrm{~m}$, second-

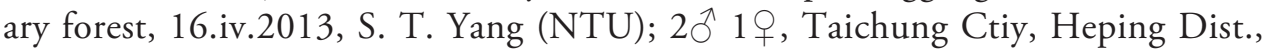
Huanshan Tribe, Ssuchiehlan Stream, 1832 m, riverbed, 26.i.2013, S. T. Yang (NTU); Mazu, Beigan Is.: 2 $\widehat{\jmath}$, Lienchiang County, Beigan Township, $100 \mathrm{~m}$, sea-

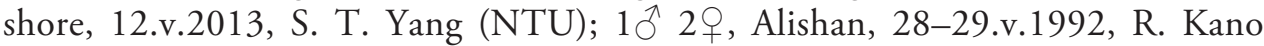
(NSMT); 19 , nr Huanshan, 2.v.2006, H. Kurahashi (NSMT); $2 \hat{0}$, Alishan-Yushan, 2,600-2,700 m, 31.x.1985, M. Iwasa (NSMT); 19, Taoyuen, Paling, 9-11. vi.1992, R. Kano (NSMT); $4 \hat{\jmath} 7$ 우, Oiwake, 4.V.1965, T. Shirozu (NSMT); 60 4ㅇ, Mt. Alishan, 10-13.VII.1964, S. Asahina (NSMT); 2, Tattaka, 24.VI.1965, T. Shirozu (NSMT); 10 , Taichung, Pilushi, 2,200 m, 22-23.v.1988, R. Davidson,

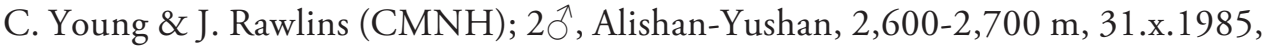
M. Iwasa (NSMT).

\section{Bellardia Robineau-Desvoidy, 1863}

\section{Bellardia menechma (Séguy, 1934)}

Materials. 10, Hualien Hsien, Juisui, 11.xi.1985, K. Kanmiya (NSMT); 1ð, Chihpen, 10.vi.1972, R. Kano (NSMT); 7ð 69, Juisui, 10-11.xi.1985, K. Kanmiya (NSMT); 2 , Chihpen, 10.vi.1973, H. M. Lin (IDD); 2 , Fenchifu, 1,405 m, 2.xi.1985, M. Iwasa (IDD); 19, Taichung Hsien, Chichiawanchi, Huanshan, 6.xi.1985, K. Kanmiya (IDD). 


\section{Bellardia pubescens (Macquart, 1851)}

Materials. $1 \widehat{\partial}$, Chia-i Hsien, Fenchi-Hu, 8.vii.1985, H. Shima (NSMT); 1 9 , Nantou Hsien, Janai (Mushia), 28.ix.1965, K. Kaneko (IDD); 1ㅇ, Lishan, 16.ix.1970, S. C. Lien (IDD); 1, Chihpen, 10.vi.1972, R. Kano (IDD).

\section{Calliphora Robineau-Desvoidy, 1830}

\section{Calliphora nigribarbis Vollenhoven, 1863}

Note. See to James (1977: 531).

\section{Calliphora pattoni Aubertin, 1931}

Materials. $1 \delta^{\lambda}$, Taichung City, Heping Dist., Wuling Farm, Taiwan Salmon Observatory Deck, 1800 m, river bed, 23.xii.2012, T. R. Tsai (NTU); 1ㅇ, Taichung Ctiy, Heping Dist., Huanshan Tribe, Ssuchiehlan Stream, 1832 m, riverbed, 26.i.2013, S. T. Yang (NTU); 3우, Taichung Ctiy, Heping Dist., Siaosyue Mt., Tianchi, 2626 m, coniferous forest, 12.ii.2013, S. T. Yang (NTU); 1 9 , Alishan-Yushan, 2,600-2,700

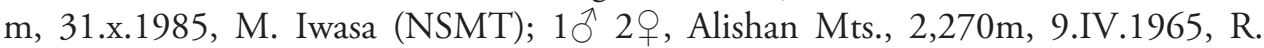
Kano, Yoshimoto \& Parkins (NSMT); 10, Tzuchung, 2,370m, 10.IV.1965, S. Ueno (NSMT); $13 \hat{\jmath}$ 59, Alishan, 28-29.v.1992, R. Kano \& H. M. Lin (NSMT); 1 , Taichung, Anmashan, 2,230 m, 30.iv-4.v.1990, A. Smetana (CMNH); 1 우, RenAi- He-Huan-Shan, LuoYing Inn, 2,830 m, 22.iii.2011, C. Young (CMNH); 1 우, Alishan-Yushan, 2,600-2,700 m, 31.x.1985, M. Iwasa (NSMT).

\section{Calliphora vomitoria (Linnaeus, 1758)}

Materials. $14 \bigcirc 10 \uparrow$, Nantou County, Ren'ai Township, Songgang, 2049 m, secondary forest, 16.iv.2013, S. T. Yang (NTU); 6ㅇ, Taichung Ctiy, Heping Dist., Wuling Farm, Taiwan Salmon Observatory Deck, 1800 m, river bed, 23.xii.2012, T. R. Tsai (NTU); $1 \overbrace{}^{\lambda}+$, Taichung City, Heping Dist., Huanshan Tribe, Ssuchiehlan Stream, 1832 m, riverbed, 26.i.2013, S. T. Yang (NTU); 3 + , Taichung Ctiy, Heping Dist., Siaosyue Mt., Tianchi, 2626 m, coniferous forest, 12.ii.2013, S. T.

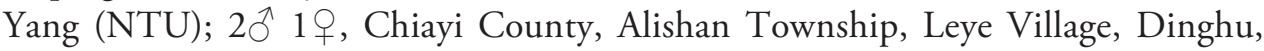
$1657 \mathrm{~m}$, secondary forest, 23.ii.2013, S. T. Yang (NTU); $1 \sigma^{\Uparrow} 1$, Alishan-Yushan, 2,600-2,700 m, 31.x.1985, M. Iwasa (NSMT); $10^{\Uparrow} 4$ 우, Taichung, Anmashan, 2,230 m, 30.iv-4.v.1990, A. Smetana (CMNH); 10, Anmashan, 2,230 m, 30.iv.4.v.1990, A. Smetana (CMNH); 1 , nr Alishan, Hishan, 2,300 m, 30.iv.2006, H. Kurahashi (NSMT); 4, Kuanshan trail at Kuanshanchi River, 2,400 m, 20-23. 
vii.1993, A. Smetana (CMNH); 60 10, Alishan, 28-29.v.1992, R. Kano \& H. M. Lin (NSMT); 1 đ 19, Alishan-Yushan, 2,600-2,700 m, 31.x.1985, M. Iwasa (NSMT); 3ㅇ, Ren-Ai- He-Huan-Shan, LuoYing Inn, 2,830 m, 22.iii.2011, C. Young $(\mathrm{CMNH})$.

Polleniopsis Townsend, 1917

*Polleniopsis dalatensis Kurahashi, 1972

Materials. 1ðึ, Nantou County, Ren'ai Township, Jianqing Farm, 26.vii.1961, J. K. Nii (NSMT); $1 \overbrace{}^{\lambda} 1$, Fanshan, 1650 m, 6.xi.1985, M. Iwasa (NSMT).

Polleniopsis toxopei (Senior-White, 1926)

Note. See to James (1977: 540).

Tainanina Villeneuve, 1926

Tainanina pilisquama (Senior-White, 1925)

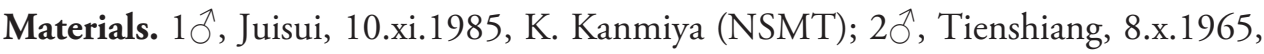
K. Kanmiya (NSMT); $1 \hat{\jmath}$, Juisui, 10.xi.1985, K. Kanmiya (NSMT).

*Tainanina sarcophagoides (Malloch, 1931)

Materials. 2甲, Tienshiang, 8.x.1965, K. Kanmiya (NSMT)

Subfamily MELANOMYINAE

Gymnadichosia Villeneuve, 1927

Gymnadichosia pusilla Villeneuve, 1927

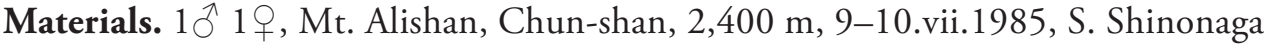

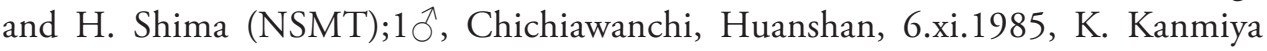
(NSMT). 
Paradichosia Senior-White, 1923

Paradichosia crinitarsis Villeneuve, 1927

Materials. $1 \delta^{\lambda}$, Nantou County, Ren'ai Township, Gaofeng, Guantou Mt. (Northeast), 20.v.2013, K. Harusawa (PCKHa); $1 \hat{\jmath}^{\hat{\gamma}} 1$, , Pingtung County, Shizi Township, Shuangliu, 189-300 m, secondary forest, 11.v.2013, S. T. Yang (NTU); 1의, Tsuifeng-Shunkan, 24.vii.1985, H. Shima (NSMT); 1엉 Shanpaling, 26.x.1985, K. Kanmiya (NSMT); 10̂, Hsinchu, Wufeng, 24.xii.1993, C. L. Chung (NSMT).

\section{Paradichosia lui sp. n.}

Paradichosia nigricans Villeneuve, 1927

Materials. 1, Nantou County, Lugu Township, Xitou, $1156 \mathrm{~m}$, secondary forest, 08.iii.2013, S. T. Yang (NTU); 1 ${ }^{\lambda}$, Taoyuen, Paling, 9-11.vi.1992, R. Kano (NSMT); 1우, Alishan, 28-29.v.1992, R. Kano (NSMT); 1우, Fanlu, Kungtien village, 15.iv.1958,

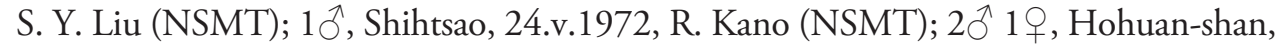
Tsuifeng, 2,400 m, 23-24.vii.1985, S. Shinonaga (NSMT); 10․ Hsitou, 1,000 m, 1.v.2006, H. Kurahashi (NSMT); 19, Alishan, 28-29.v.1992, R. Kano (NSMT).

Pollenomyia Séguy, 1935

Pollenomyia sinensis (Séguy)

Materials. $1{ }^{\Uparrow}$, Miaoli, Nanchung, 22.xii.1993, C. L. Chung (NSMT).

Tricycleopsis Villeneuve, 1927

Tricycleopsis paradoxa Villeneuve, 1927

Note. See to James (1977: 540).

Subfamily BENGALIINAE

Bengalia Robineau-Desvoidy, 1830

*Bengalia calilungae Rueda, 1985

Materials. 1ð, Penpuchi (Honbukei), 21.viii.1980, K. Hara (NSMT). 


\section{*Bengalia chekiangensis Fan, 1965}

Materials. $3 \overbrace{}^{\Uparrow} 2$, Nantou, Wushe, 24.v.1988, C. Young, J. Rawlins \& R. Davidson (CMNH); 19, Kaohsiung, Shanping, 640 m, 11-20.v.1988, J. Rawlins, C. Young, \& R. Davidson (CMNH); $7 ð$ 9ㅇ, Nantou, Wushe, 24.v.1988, C. Young, J. Rawlins \& R. Davidson (CMNH).

\section{Bengalia emarginata Malloch, 1927}

Materials. 10 , Nantou County, Ren'ai Township, Aowanda, 18.v.2013, K. Harusawa (PCKHa); 10․ Pingtung County, Shizi Township, Shuangliu, 189-300 m, secondary forest, 11.v.2013, S. T. Yang (NTU); 3ð, Taiton, Tsupun, 21.iii.1981, M. Iwasa (NSMT); 1우 Hotso (Roshan), 30.ix.1965, K. Kaneko (NSMT); 1 , Kaohsiung, Shanping, 640 m, 11-20.iv.1988, C. Young, J. Rawlins \& R. Davidson (CMNH); 1ð̂, Kotzulin, 850m, 4.IV.1965, S. Ueno (NSMT); 10̄, Alishan, 10-13. VII.1964, S. Asahina (NSMT); 10, Fenchihu, 1,370m, 11.IV.1965, B. D. Par-

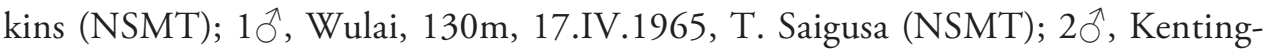
kungyuan, 2-3.IV.1965, R. Kano (NSMT); 19, Kuantzuling, 250m, 6.IV.1965, R. Kano (NSMT); $3{ }^{\Uparrow} 1$ 1 , Nanzan-kei, 30.IV.1965, 8.V.1965, T. Shirozu (NSMT); 10, Chihpen Hot Spring, 3-4.vi.1992, R. Kano (NSMT); 10, Chung-Hsien University, Huei-sun Forest, 21.v.1992, R. Kano (NSMT); 10, Kenting Park, 1-2. vi.1992, R. Kano (NSMT); 1 , Nantou, Wushe, 24.v.1988, C. Young, J. Rawlins $\&$ R. Davidson $(\mathrm{CMNH})$.

\section{Bengalia escheri Bezzi, 1913}

Materials. 1엉 Nantou County, Ren'ai Township, Aowanda, 18.v.2013, K. Harusawa (PCKHa); $3 \hat{\jmath}$, Taipei City, Neihu Dist., Daluntou Mt., $352 \mathrm{~m}$, secondary forest, 19.v.2013, S. T. Yang (NTU); 10̂, New Taipei City, Wulai Dist., Hsiaoi Village, Tonghou, 233 m, dump (at light), 30.v.2012, S. T. Yang (NTU); 1우, Kaohsiung, Shanping, 640 m, 21-30.iv.1988, C. Young, R. Davidson \& J. Rawlins (CMNH); $1 \hat{\jmath}$, Fenchihu, 1,370m, 10.IV.1965, R. Kano (NSMT); 10 1 1 , Fenchihu, 4.IV.1965, 12.IV.1965, R. Kano (NSMT); 1우 Ten-chih, 23-04-03 N, 120-45-13 E, 1,550 m, 23.viii.1996, C. W. Young (CMNH); 10̄, Taoyuen, Paling, 9-11.vi.1992, R. Kano (NSMT); 2 , Lushan, 1,000m, 24-25.VII.1985, S. Shinonaga (NSMT); $10^{\Uparrow} 1+$, Kukan, 3.XI.1985, K. Kanmiya (NSMT); 10, Nanshanchi, 31.iii.1996, R. Matsumoto (BLKU); 19, Wulai-hsiang, Fushan, 400-600 m, 28.xi.1997, T. Tachi (BLKU); 80 19, Fushan B. G., 600 m, 3-6.v.2006, H. Kurahashi (NSMT); 10, Chiapaotai Park, 4.x.1985, K. Kanmiya (NSMT). 


\section{Bengalia fuscipennis Bezzi, 1913}

Materials. 10, Nantou County, Puli Township, Shizitou, at light, 20.v.2013, K. Harusawa (PCKHa); 1 , , Nantou County, Ren'ai Township, Gaofeng, Guantou Mt. (Northeast), 20.v.2013, K. Harusawa (PCKHa); $2 \hat{0}$, New Taipei City, Wulai Dist., Hsiaoi Village, Tonghou, 233 m, dump (at light), 30.v.2012, S. T. Yang (NTU); 16 7ㅇ, Fushan B. G., 600 m, 3-6.v.2006, H. Kurahashi (NSMT); 2q, Wulai, 150m, 17. IV.1965, 20.X.1985, R. Kano \& K. Kanmiya (NSMT); 1 , Lafu, 350m, 27.X.1985, R. Kano (NSMT); 1 ○ึ 3 으, Fenchifu, 1,400m, 5.VII.1985, 8.VII.1985, S. Shinonaga $\&$ H. Shima (NSMT); $5{ }^{\wedge} 2$, , Lenai, 1,000m, 23.VII.1985, S. Shinonaga (NSMT); 1ㅇ, Tattaka, 29.VI.1965, T. Shirozu (NSMT); 2ㅇ, Kaohsiung, Shanping, 640 m, 21-30.iv.1988, C. Young, J. Rawlins \& R. Davidson (CMNH); 20, Chiapaotai Park, 4.x.1985, K. Kanmiya (NSMT); $1 \overbrace{}^{\Uparrow} 5$, , Kaohsiung, Shanping, 640 m, 2130.iv.1988, C. Young, R. Davidson \& J. Rawlins (CMNH); 2 으, Kaohsiung, Shan-

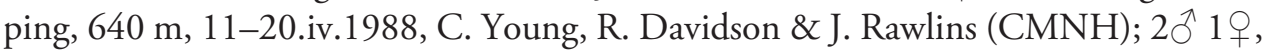
Chung-Hsien University, Huei-sun Forest, 21.v.1992, R. Kano (NSMT).

\section{Bengalia taksina (Lehrer, 2005)}

Materials. 1q, Nanshanchi, 31.iii.1996, R. Matsumoto (BLKU); 50 5 9 , Nantou, Wushe, 24.v.1988, C. Young, J. Rawlins \& R. Davidson (CMNH); 10, Kaohsiung, Shanping, 640 m, 21-30.iv.1988, C. Young, R. Davidson \& J. Rawlins (CMNH); 10 , Nantou, Wushe, 640 m, 24.v.1988, C. Young, J. Rawlins \& R. Davidson (CMNH); 2 을 Taoyuen, Paling, 9-11.vi.1992, R. Kano (NSMT); 3ô 1q, Kuantzuling, 28.v.1992, R. Kano (NSMT); $2 \hat{\jmath} 1$ 1 , Puli, Nanshanhsi, 23-24.v.1992, R. Kano (NSMT); $2 \hat{\jmath}$ 1옹 Chung-Hsien University, Huei-sun Forest, 21.v.1992, R. Kano (NSMT).

\section{Bengalia torosa (Wiedemann, 1819)}

Materials. 2q, Kaohsiung, Shanping, 640 m, 1-10.iv.1988, R. Davidson, J. Rawlins \& C. Young $(\mathrm{CMNH})$; 10, Kaohsiung, Shanping, 640 m, 21-30.iv.1988, C. Young, J. Rawlins \& R. Davidson (CMNH).

\section{Bengalia varicolor (Fabricius, 1805)}

Materials. $1 \circlearrowleft 1$, Nantou County, Ren'ai Township, Aowanda, 18.v.2013, K. Harusawa (PCKHa); 2q, Nantou County, Ren'ai Township, Aowanda, 21.v.2013, K.

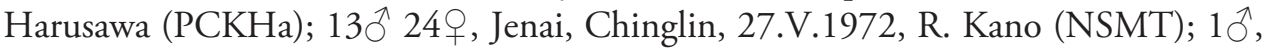
Nanzan-kei, 26.VI.1965, T. Shirozu (NSMT); 10 , Kenting-kung-yuan, 2.IV.1965,

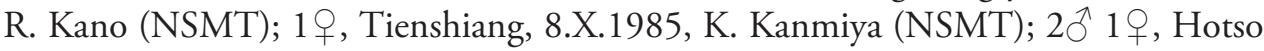
(Roshan), 30.IX.1965, K. Kaneko (NSMT). 


\section{Subfamily LUCILIINAE \\ Hemipyrellia Townsend, 1918}

\section{Hemipyrellia ligurriens (Wiedemann, 1830)}

Materials. $1 \widehat{ }{ }^{\lambda}$, Nantou County, Puli Township, Qianxi, 20.v.2013, K. Harusawa (PCKHa); $3 \hat{7} 7$, , Yilan County, Nan'ao Township, $22 \mathrm{~m}$, secondary forest; eggs collected, 7.iii.2013 eclosion, 16.ii.2013, S. T. Yang (NTU); 4ㅇ, Tainan City, Baihe Dist., Guanziling, Lingding Park, 322 m, secondary forest, 21.iii.2013, S. T. Yang (NTU); 1, New Taipei City, Shimen Dist., Linshan Cape, 20 m, seashore, 29.xii.2012, S. T. Yang (NTU); 19, New Taipei City, Xindian Dist., Zhitan Dam, 57 m, riverside, 27.xii.2012, S. T. Yang (NTU); 19, Hualien County, Xiulin Township, Fushi, Changuang Temple, 120 m, monsoon rainforest, 09.v.2013, S. T. Yang (NTU); Orchid Is.: 1 ${ }^{\lambda}$, Taitung County, Lanyu Township, Hongtou, Weather Station, $231 \mathrm{~m}$, tropical rainforest, 01.vi.2013, S. T. Yang (NTU); Orchid Is.: 1 9 , Taitung County, Lanyu Township, Zhong'ai Bridge, 53 m, tropical rainforest, 01.vi.2013, S. T. Yang (NTU); $18 \hat{\jmath} 22$, Hualien County, Shoufeng Township, Pinghe, $41 \mathrm{~m}$, plain; eggs collected, 7.iii.2013 eclosion, 16.ii.2013, S. T. Yang (NTU); Mazu, Beigan

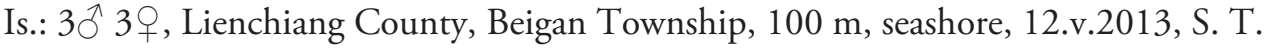
Yang (NTU); $2 \widehat{\jmath}$ 1q, Kaohsiung City, Liugui Dist., Tsaidie Valley, 366 m, secondary forest, 31.iii.2013, S. T. Yang (NTU); 5012 ㅇ, New Taipei City, Wulai Dist., Zhongzhi, 109 m, riverside; eggs collected, 18.i.2013 eclosion, 27.xii.2012, S. T. Yang (NTU); 10 1 5 , Hualien County, Xincheng Township, Qixingtan, Sihba Height, 41 m, grassland, 09.v.2013, S. T. Yang (NTU); 5우, Hualien County, Xincheng Township, Qixingtan, $14 \mathrm{~m}$, seashore, 09.v.2013, S. T. Yang (NTU); 50 4우, Pingtung County, Sangdimen Township, Sandi Village, $381 \mathrm{~m}$, secondary forest, 2.iv.2013, S. T. Yang (NTU); 1어, New Taipei City, Zhonghe Dist., Yuantong Temple, 173 m, secondary forest, 25.v.2013, S. T. Yang (NTU); $2 \hat{\jmath} 2$ ㅇ, Yilan County, Toucheng Township, Beiguan, 34 m, seashore, 04.iv.2013, S. T. Yang (NTU); $2 \hat{\jmath} 1$, , Chiayi County, Alishan Township, Shanmei, Tanayiku, $450 \mathrm{~m}$, secondary forest, 24.ii.2013,

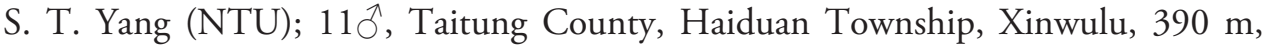
secondary forest, 30.v.2013, S. T. Yang (NTU); $1 \delta^{\lambda} 3$, Taitung County, Luye Township, Ruiyuan, 198 m, farmland, 30.v.2013, S. T. Yang (NTU); 2§, Taitung County, Luye Township, Luye High Terrace, 353 m, grassland, 30.v.2013, S. T. Yang

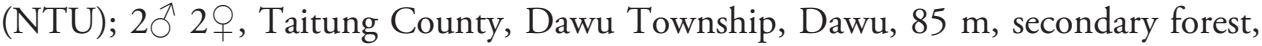
18.iv.2013, S. T. Yang (NTU); Liuqiu Is.: $2 \widehat{\jmath} 1$, , Pingtung County, Liuqiu Township, Geban Bay, 10 m, seashore, 04.v.2013, S. T. Yang (NTU); Liuqiu Is.: 80ึ 2울, Pingtung County, Liuqiu Township, Shanfu, 25 m, seashore, 04.v.2013, S. T. Yang

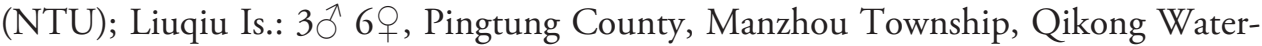
fall, 40-125 m, secondary forest, 24.i.2013, S. T. Yang (NTU); 50 2 9 , Kaohsiung City, Jiaxian Dist., Jiaxian, 278 m, secondary forest, 12.v.2013, S. T. Yang (NTU);

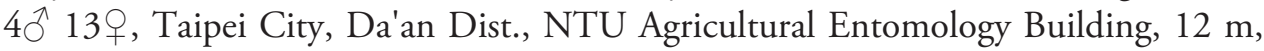
orchard; eggs collected, 05.ii.2013 eclosion, 22.i.2013, S. T. Yang (NTU); 19, Taipei 
City, Da'an Dist., NTU Agricultural Entomology Building, 12 m, orchard, 22.i.2013, S. T. Yang (NTU); 1 $\hat{\jmath}$, Taipei City, Da'an Dist., NTU Agricultural Entomology Building, $12 \mathrm{~m}$, orchard, 01.iv.2013, S. T. Yang (NTU); 19 $\overbrace{}^{11}$ 우, Taipei City, Da'an Dist., NTU Agricultural Entomology Building, 12 m, orchard; eggs collected, 20.xii.2012 eclosion, 19.viii.2009, S. T. Yang (NTU); 7 $\hat{~} 1$ 우, Taipei City, Da'an Dist., Fuzhoushan Park, 71 m, secondary forest, 17.iii.2013, S. T. Yang (NTU); 2 q, Taipei City, Da'an Dist., Fuzhoushan Park, 100 m, secondary forest, 17.iii.2013, S.

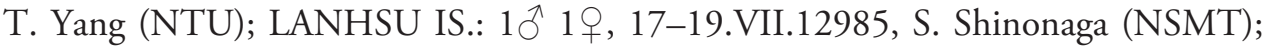
1오, Wulai, 4.VII.1985, S. Shinonaga (NSMT); 10, Kenting Park, 1-2.vi.1992, R. Kano (NSMT); $10^{\Uparrow} 1$, , Kuatsuling, ll.VII.1985, S. Shinonaga (NSMT); 10, Shu Lin, 16.VIII.1987, I. Togashi (IAC); 10 19, Santimen, 13.VII.1985, S. Shinonaga (NSMT); 10, Juisui, 10.XI.1985, K. Kanmiya (NSMT); 10 1ㅇ, Taipei City, 20-17. III.1965, R. Kano (NSMT); $3 \widehat{\jmath}$, Liuknei, 12.VII.1985, H. Shima (NSMT); $1 \hat{\jmath} 1$, Kuatsuling, 10-11.VII.1985, H. Shima (NSMT); 8ภ 19, Chihpen, 15.XI.1985, K. Kanmiya (NSMT); $5 \hat{\jmath} 3$, Antung, 12.XI.1985, K. Kanmiya (NSMT); $1 \overbrace{}^{\lambda} 2$, Chihpen Hot Spring, 3-4.vi.1992, H. M. Lin (NSMT); 10 J Jiji (Chichi), 30.iv.2006, H. Kurahashi (NSMT); $3 \hat{\jmath}$, Kuantzuling, 26.v.1992, R. Kano (NSMT).

\section{Lucilia Robineau-Desvoidy, 1830}

\section{Lucilia bazini Séguy, 1934}

Materials. Mazu, Beigan Is.: 1q, Lienchiang County, Beigan Township, $100 \mathrm{~m}$, seashore, 12.v.2013, Y. C. Yu (NTU); 19, Kaohsiung, Shanping, 640 m, 23-31.iii.1988,

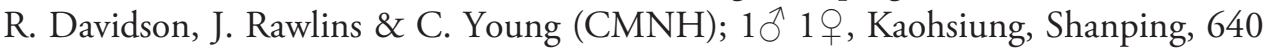
m, 21-30.iv.1988, R. Davidson, J. Rawlins \& C. Young (CMNH).

\section{Lucilia calviceps Bezzi, 1927}

Materials. 2ð, Chihpen, 20.VII.1985, 15.XI.1985, S. Shinonaga (NSMT); 1ð, Chuchi, 120m, 14.IV.1965, R. Kano (NSMT); 1, Yuankan-Tsuifen, 23.VII.1985, H. Shima (NSMT).

\section{Lucilia cuprina (Wiedemann, 1830)}

Materials. 1ð, Hualien County, Xincheng Township, Qixingtan, $14 \mathrm{~m}$, seashore, 09.v.2013, S. T. Yang (NTU); 1 , Hualien County, Xincheng Township, Qixingtan, Sihba Height, 41 m, grassland, 09.v.2013, S. T. Yang (NTU); 1 9 , Chiayi County, Alishan Township, Shanmei, Tanayiku, $450 \mathrm{~m}$, secondary forest, 24.ii.2013, S. T. Yang (NTU); 1 , Fenchifu, 1,400m, 8.VII.1985, S. Shinonaga (NSMT); $1 \overbrace{}^{\Uparrow}$, Kwan- 
tyling, 11.VII.1985, S. Shinonaga (NSMT); 1옹 Shanpaling, 27.x.1985, K. Kanmiya (NSMT); 1 9 , Taipei, 30.III.1965, R. Kano (NSMT); 1 + , Taipei, 4.III.1981, M. Iwasa (NSMT); 1 으, Laanung, 11.VII.1985, S. Shinonaga (NSMT); $1 \hat{\jmath} 1$ 우, San Palin, 1,100m, 25.X.1985, R. Kano (NSMT); 10, Pinton, 6.III.1981, M. Iwasa (NSMT); $2 \widehat{\jmath} 2$, , Shanpaling, 27.X.1985, K. Kanmiya (NSMT); 10, Kwantyling, 11.VII.1985, S. Shinonaga (NSMT); 1q, Shanpaling, 27.x.1985, K. Kanmiya (NSMT).

\section{Lucilia hainanensis Fan, 1965}

Materials. $2 \hat{\jmath}$, Nantou County, Ren'ai Township, Gaofeng, Guantou Mt. (Northeast),

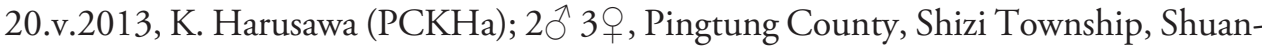
gliu, 189-300 m, secondary forest, 11.v.2013, S. T. Yang (NTU); 49, Taitung County, Haiduan Township, Xinwulu, 390 m, secondary forest, 30.v.2013, S. T. Yang (NTU); 5ㅇ, Taitung County, Dawu Township, Dawu, 85 m, secondary forest, 18.iv.2013, S. T. Yang (NTU); 2q, Taitung County, Haiduan Township, Xiama, $790 \mathrm{~m}$, secondary forest, 30.v.2013, S. T. Yang (NTU); 1 9 , Chiayi County, Alishan Township, Shanmei, Tanayiku, $450 \mathrm{~m}$, secondary forest, 24.ii.2013, S. T. Yang (NTU); $2 \hat{\jmath} 30$ ㅇ, Kaohsiung City, Liugui Dist., Tsaidie Valley, 366 m, secondary forest, 31.iii.2013, S.

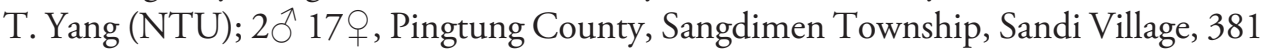
$\mathrm{m}$, secondary forest, 2.iv.2013, S. T. Yang (NTU); $20 \AA 10$ ㅇ, Kaohsiung, Shanping, 640 m, 11-20.iv.1988, 21-30.iv.1988, 1-10.v.1988, R. Davidson, J. Rawlins \& C. Young (CMNH); 1우, Taichung, Anmashan, 2,230 m, 30.iv-4.v.1990, A. Smetana (CMNH); 10, Anmashan, 2,230 m, 30.iv.-4.v.1990, A. Smetaana (CMNH).

\section{Lucilia papuensis Macquart, 1842}

Materials. 1 , Nantou County, Lugu Township, Xitou, 1156 m, secondary forest, 08.iii.2013, S. T. Yang (NTU); 1 9 , Taitung County, Beinan Township, Jhihben, 209 m, secondary forest, 15.ii.2013, S. T. Yang (NTU); 1오, Nantou County, Yuchi Township, Sun Moon Lake, 803 m, lakeside, 20.i.2013, S. T. Yang (NTU); 1우, Taitung County, Beinan Township, Jhihben, 209 m, secondary forest, 15.ii.2013, S. T. Yang (NTU); 1ㅇ, Juisui, 11.XI.1985, K. Kanmiya (NSMT); 3을 Lushan, 1,000m, 24-25.VII.1985, S. Shinonaga (NSMT); 2q, Chihpen, 15.XI.1985, K. Kanmiya (NSMT); 2 , Tenchih, 23-04-03 N, 120-45-13 E, 1,550 m, 23.viii.1996, C. W. Young (CMNH); 1ㅇ, Kuantzuling, 250m, 6.IV.1965, R. Kano (NSMT); 1언, Lenai, 1,000m, 23.VII.1985, S. Shinonaga (NSMT); 1 9 , Fushan B. G., 600 m, 3-6.v.2006, H. Kurahashi (NSMT); 1우, Nanshanchi, 1.v.2006, H. Kurahashi (NSMT); 6웅 Kaohsiung, Shanping, 640 m, 1-10.v.1988, R. Davidson, J. Rawlins \& C. Young (CMNH); 1 우, Kaohsiung, Shanping, 640 m, 11-20.iv.1988, J. Rawlins, C. Young, R. Davidson (CMNH); 3 9, Meifeng, 2,130 m, 10-17.vii.1993, A. Smetana (CMNH); 69, Taoyuen, Paling, 9-11.vi.1992, R. Kano (NSMT); 1 9 , Taichung, Anmashan, 2,230 m, 30.iv.1990, A. Smetana (CMNH). 


\section{Lucilia porphyrina (Walker, 1857)}

Materials. $1 \delta$, Nantou County, Ren'ai Township, Aowanda, 21.v.2013, K. Harusawa (PCKHa); 4 , Nantou County, Ren'ai Township, Aowanda, 18.v.2013, K. Harusawa (PCKHa); 2 , , Nantou County, Ren'ai Township, Gaofeng, Guantou Mt. (Northeast), 20.v.2013, K. Harusawa (PCKHa); 21 $\hat{\jmath} 23$, Yilan County, Datong Township, Cilan, 394 m, secondary forest; eggs collected, $11 . i i .2013$ eclosion, 27.i.2013, S. T. Yang (NTU); 1 3 9 , Chiayi County, Alishan Township, Shanmei, Tanayiku, 450 m, secondary forest, 24.ii.2013, S. T. Yang (NTU); 3 ㅇ, Taipei City, Neihu Dist., Daluntou Mt., 352 m, secondary forest, 19.v.2013, S. T. Yang (NTU);

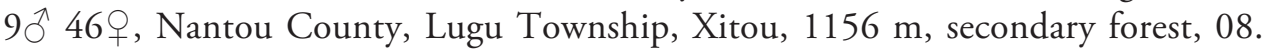
iii.2013, S. T. Yang (NTU); $19 \hat{\jmath} 28$, Nantou County, Lugu Township, Xitou, 1156 m, secondary forest; eggs collected, 26.iii.2013 eclosion, 08.iii.2013, S. T.

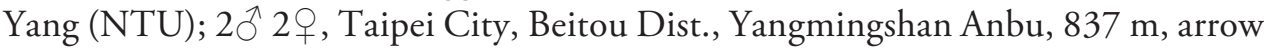
bamboo forest, 31.i.2013, S. T. Yang (NTU); $8 \AA 19+$, New Taipei City, Wulai Dist., Xinxian Village, 219 m, riverside, 16.iii.2013, S. T. Yang (NTU); 7, New Taipei City, Wulai Dist., Hsiaoi Village, Tonghou, 233 m, riverside, 27.xii.2012, S. T. Yang (NTU); 6ภ 7ㅇ, New Taipei City, Wulai Dist., Hsiaoi Village, Tonghou, $233 \mathrm{~m}$, riverside; eggs collected, 18.i.2013 eclosion, 27.xii.2012, S. T. Yang (NTU); $9+$, Taoyuan County, Fuxing Township, Baling, 640 m, secondary forest, 07.i.2013, S. T. Yang (NTU); 1오 Nantou County, Ren'ai Township, Meifeng Farm, 2100 m, secondary forest, 24.x.2009, S. T. Yang (NTU); 10, Tainan City, Baihe Dist., Guanziling, Red-Leaf Park, 357 m, secondary forest, 21.iii.2013, S. T. Yang (NTU); $12{ }^{\wedge} 9$, , New Taipei City, Wugu Dist., Guanyin Mt., Yinghan Peak, 359-611 m, secondary forest, 30.iv.2013, S. T. Yang (NTU); 2 , Taichung City, Heping Dist., Guguan, Songhe Tribe, 700 m, secondary forest, 14.iv.2013, S. T. Yang (NTU); 10, Taichung City, Heping Dist., Huanshan Tribe, Ssuchiehlan Stream, 1832 m, riverbed; larvae collected, 09.ii.2013 eclosion, 26.i.2013, S. T. Yang (NTU); 10̄, Nantou County, Ren'ai Township, Qingjing Farm, 1911 m, secondary forest, 16. iv.2013, S. T. Yang (NTU); 2q, New Taipei City, Xindian Dist., Zhitan Dam, 57 m, riverside, 27.xii.2012, S. T. Yang (NTU); 7우, Pingtung County, Shizi Township, Shuangliu, $352 \mathrm{~m}$, secondary forest, 11.v.2013, S. T. Yang (NTU); 34035 , Yilan County, Su'ao Township, $28 \mathrm{~m}$, rural area; eggs collected, 7.iii.2013 eclosion,

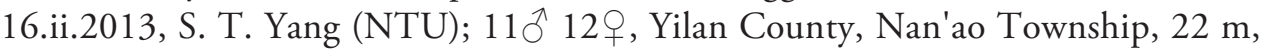
secondary forest; eggs collected, 7.iii.2013 eclosion, 16.ii.2013, S. T. Yang (NTU); 2ㅇ, Yilan County, Nan'ao Township, $22 \mathrm{~m}$, secondary forest, 16.ii.2013, S. T. Yang (NTU); 4ㅇ, New Taipei City, Wulai Dist., Zhongzhi, 109 m, riverside,27. xii.2012, S. T. Yang (NTU); 50 249, New Taipei City, Wulai Dist., Zhongzhi, 109 m, riverside; eggs collected, 18.i.2013 eclosion,27.xii.2012, S. T. Yang (NTU); 10우, Chiayi County, Alishan Township, Leye Village, Dinghu, 1657 m, secondary forest, 23.ii.2013, S. T. Yang (NTU); $21{ }^{\lambda} 25$, Chiayi County, Alishan Township, Leye Village, Dinghu, 1657 m, secondary forest; eggs collected, 18.iii.2013 eclosion,

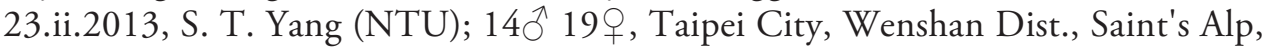


$144 \mathrm{~m}$, secondary forest; eggs collected, 08.i.2013 eclosion, 21.xii.2013, S. T. Yang (NTU); 2へ 19, Taipei City, Wenshan Dist., Saint's Alp, 144 m, secondary forest, 21.xii.2013, S. T. Yang (NTU); 1ㅇ, Taipei City, Wenshan Dist., Saint's Alp, 144 m, secondary forest, 20.xii.2013, S. T. Yang (NTU); 2ㅇ, New Taipei City, Ruifang Dist., Jinguashih, 360 m, house, 05.ii.2013, T. H. Wu (NTU); 90 22 9 , Taipei City, Da'an Dist., NTU Agricultural Entomology Building, $12 \mathrm{~m}$, orchard; eggs

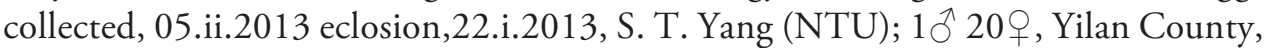
Toucheng Township, Beiguan, 34 m, seashore, 04.iv.2013, S. T. Yang (NTU); 10 9오, New Taipei City, Shimen Dist., Linshan Cape, 20 m, seashore, 29.xii.2012, S.

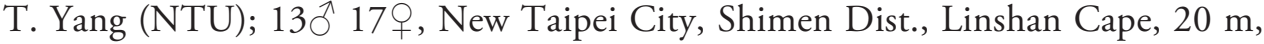
seashore; eggs collected, 21.i.2013 eclosion, 29.xii.2012, S. T. Yang (NTU); $1 \delta^{\lambda}$ 17우, Yilan County, Toucheng Township, Yingzi Mt., 936 m, bush, 27.v.2013, S. T. Yang (NTU); 19, Taitung County, Haiduan Township, Xiama, 790 m, secondary forest, 30.v.2013, S. T. Yang (NTU); Mazu, Beigan Is.: $1 \delta^{\Uparrow} 1$, , Lienchiang County, Beigan Township, 100 m, seashore, 12.v.2013, Y. C. Yu (NTU); $9 \lambda_{10}$, New Taipei City, Pingxi Dist., Lingjiao, 213 m, secondary forest; eggs collected,

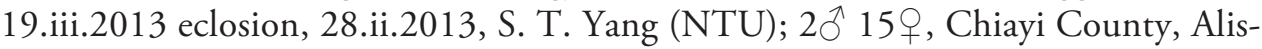
han Township, Leye Village, Zhunghu, 1383 m, secondary forest, 23.ii.2013, S. T. Yang (NTU); 1 $\overbrace{}^{\lambda}$, Taitung County, Beinan Township, Jhihben, 209 m, secondary forest, 15.ii.2013, S. T. Yang (NTU); $1{ }^{\Uparrow}$, New Taipei City, Shiding Dist., Tanyao, 300 m, lakeshore, 2.ii.2013, S. T. Yang (NTU); $2 \hat{\jmath} 3$ ㅇ, Taipei City, Da'an Dist., Fuzhoushan Park, $71 \mathrm{~m}$, secondary forest, 17.iii.2013, S. T. Yang (NTU); 209 , New Taipei City, Ruifang Dist., Jinguashih, Chahu Mt., 416 m, bush, 01.ii.2013, S. T. Yang (NTU); 21 9 , New Taipei City, Ruifang Dist., Jinguashih, Chahu Mt., 343 m, bush, 01.ii.2013, S. T. Yang (NTU); 15 36우, New Taipei City, Ruifang Dist., Jinguashih, Chahu Mt., 343 m,bush; eggs collected, 19.ii.2013 eclosion,01.

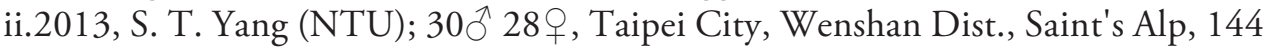
m, secondary forest; eggs collected, 08.i.2013 eclosion, 20.xii.2013, S. T. Yang

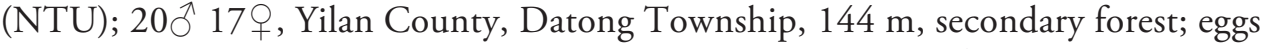
collected, 11.ii.2013 eclosion, 27.i.2013, S. T. Yang (NTU); 19, Hualien County, Guangfu Township, 143 m,plain,16.ii.2013, S. T. Yang (NTU); $3 \hat{\jmath} 8$, , Chiayi County, Zhuqi Township, Shizhao, $774 \mathrm{~m}$, secondary forest; eggs collected, 18. iii.2013 eclosion, 23.ii.2013, S. T. Yang (NTU); 4우, New Taipei City, Gongliao Dist., Shuangyu, 16 m, secondary forest; eggs collected, 19.iii.2013 eclosion, 28. ii.2013, S. T. Yang (NTU); 2 , Chiayi County, Alishan Township, Dingshizhao, $1446 \mathrm{~m}$, secondary forest, 24.ii.2013, S. T. Yang (NTU); 6010 , New Taipei City, Sanzhi Dist., Beixinzhuang, 327 m, secondary forest, 31.i.2013, S. T. Yang (NTU); 9, New Taipei City, Gongliao Dist., Santiago Cape, 97 m, bush, 28. ii.2013, S. T. Yang (NTU); $21 ð 18$, Yilan County, Su'ao Township, Nanfang'ao, 336 m, seashore; eggs collected, 7.iii.2013 eclosion, 16.ii.2013, S. T. Yang (NTU); $1{ }^{\Uparrow} 2$, , New Taipei City, Xindian Dist., Qingtan, Sishifen, 419 m, secondary forest, 07.ii.2013, S. T. Yang (NTU); $16 \AA 22$, Chiayi County, Fanlu Township, 
Xiding, 1247 m, secondary forest; eggs collected, 18.iii.2013 eclosion, 23.ii.2013, S.

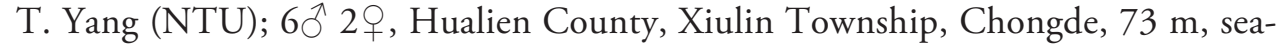
shore, 16.ii.2013, S. T. Yang (NTU); 4, Hualien County, Xiulin Township, Fushi, Changuang Temple, $120 \mathrm{~m}$, monsoon rainforest, 09.v.2013, S. T. Yang (NTU); 1 ภ 4q, nr Huanshan, 2.v.2006, H. Kurahashi (NSMT); 8014 , Fushan B. G., 600 m, 3-6.v.2006, H. Kurahashi (NSMT); $3 \hat{\jmath} 4$, Nanshanchi, 1.v.2006, H. Kurahashi (NSMT); 1ð̄, Kaohsiung, Shanping, 640 m, 21-30.iv.1988, C. Young, R. Davidson \& J. Rawlins (CMNH); $1 \delta^{\lambda} 7$, Kaohsiung, Shanping, 640 m, 21-30. iv.1988, 11-20.v.1988, R. Davidson, J. Rawlins \& C. Young (CMNH); $3 \jmath^{\lambda}$ ㅇ, Hsito, 1,000 m, 1.v.2006, H. Kurahashi (NSMT); $2{ }^{\Uparrow}$ 6q, Taichung, Anmashan, 2,230 m, 30.iv-4.v.1990, A. Smetana (CMNH); 2ð, Meifend, 2,130 m, 10-17.

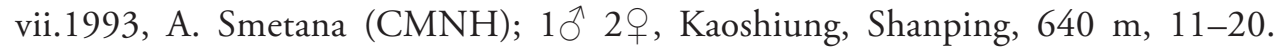
iv.1988, J. Rawlins, C. Young and R. Davidson (CMNH); 1 , Kuanshan trail at Kuanshanchi River, 2,400 m, 20-23.vii.1993, A. Smetana (CMNH); 10 , Anmashan, 2,230 m, 30.iv.-4.v.1990, A. Smetaana (CMNH); $2 \jmath^{\Uparrow} 2$, , Ten-chih, 2304-03N, 120-45-13E, 1,550 m, 23.viii.1996, C. W. Young (CMNH); 1 , , Puri, 27.III.1981, M. Iwasa (NSMT); $2 \widehat{\jmath} 1$ q , Hohuan-shan, Tsuifeng, 2,400m, 23-24. VII.1985, S. Shinonaga (NSMT); 10 , Tsuifeng, 19.vi.1970, H. Kurahashi (NSMT); $3{ }^{\lambda} 1$ ㅇ, Fenchifu, 1,400m,12.IV.1965, 8.VII.1985, 20.XI.1985, K. Kanmiya, R. Kano \& H. M. Lin (NSMT); 1 q, Hohuan-shan, Yuankang, 2,700m, 23.VII.1985, S. Shinonaga (NSMT); 2 , Huanshan, Chichiawanchi, 4.XI.1985, K. Kanmiya, R. Kano \& H. M. Lin (NSMT); 7, Alishan, 2,400m, 9-10.VII.1985, H. M. Lin \& H. Shima (NSMT); 3 + , Mt. Yangming shan, 450m, 28.III.1965, 8.VII.1985, R. Kano \& S. Shinonaga (NSMT); 1 , Chiapaotai, 4.XI.1985, K. Kanmiya, R. Kano \& H. M. Lin (NSMT); 3ð 15 , Lala shan, 1,400-1,600m, 25-26.X.1985, R. Kano

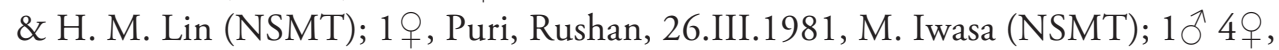
Shanpaling, 26.X.1985, K. Kanmiya (NSMT); 1q, Taiton, Tsupun, 21.III.1981,

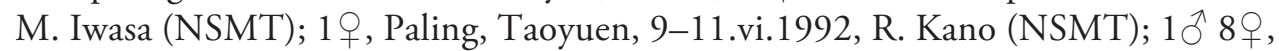
Alishan, 28-29.v.1992, R. Kano (NSMT); 2ત 17을 Chung-Hsien University, Huei-sun Forest, 21.v.1992, R. Kano (NSMT); 30 4 4ㅇ, Puli, Nanshanhsi, 2324.v.1992, H. M. Lin (NSMT); 50 24오. Taoyuen, Paling, 9-11.vi.1992, R. Kano (NSMT); 1 q , Kenting Park, 1-2.vi.1992, R. Kano (NSMT); $2 \jmath^{2}$, , Taoyuen, Lalashan, 12.vi.1992, H. M. Lin (NSMT); 1q, Tattaka, 1.VI.1965, T. Shirozu (NSMT).

\section{Lucilia sinensis Aubertin, 1933}

Materials. 19 , Nanzan-kei, 27.V.1965, T. Shirozu (NSMT); 1ð̊, Hohuan-shan, Yuankang, 2,700m, 23.VII.1985, S. Shinonaga (NSMT); 2ㅇ, Kenting Park, 17.X.1985, K. Kanmiya (NSMT); 1 , , Mt. Yuishan, 2,700-3,500m, 6-7.VII.1985, S. Shinonaga (NSMT). 


\section{Lucilia sericata (Meigen, 1826)}

Materials. $60^{\lambda} 4$, Taichung City, Heping Dist., Huanshan Tribe, Ssuchiehlan Stream, 1832 m, riverbed; larvae collected, 09.ii.2013 eclosion, 26.i.2013, S. T. Yang (NTU); 19, Fenchifu, 1,370m, 11.IV.1965, R. Kano (NSMT); 10̂, Huanshan, Chichiawanchi, 6.XI.1985, K. Kanmiya, R. Kano \& H. M. Lin (NSMT); 10ે, Taipei City, 30.III.1965, S. Miyamoto (NSMT).

\section{Lucilia taiwanica Kurahashi \& Kano, 1995}

Materials. 2§, Nantou County, Ren'ai Township, Aowanda, 18.v.2013, K. Harusawa

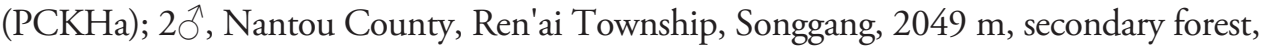
16.iv.2013, S. T. Yang (NTU); 1 , , Nantou County, Ren'ai Township, Meifeng Farm, 2100 m, secondary forest, 24.x.2009, S. T. Yang (NTU); 1옹 Nantou County, Lugu Township, Xitou, 1156 m, secondary forest, 08.iii.2013, S. T. Yang (NTU); 1 , , New Taipei City, Wugu Dist., Guanyin Mt., Yinghan Peak, 359-611 m, secondary forest, 30.iv.2013, S. T. Yang (NTU); 4q, Fushan B. G., 600 m, 3-6.v.2006, H. Kurahashi (NSMT); 2 9 , Ten-chih, 23-04-03 N, 120-45-13 E, 1,550 m, 23.viii.1996, C. W. Young (CMNH).

\section{Subfamily PHUMOSIINAE}

Caiusa Surcouf, 1919

\section{Caiusa indica Surcouf, 1914}

Materials. $1{ }^{\lambda}$, Shanping, 640 m, 21-30.iv.1988, C. Young, R. Davidson and J. Rawlins $(\mathrm{CMNH})$.

Caiusa testacea Senior-White, 1923

Note. See to Hennig (1941: 180).

\section{Caiusa sp.}

Materials. $7 \hat{\jmath} 4$, New Taipei City, Xindian Dist., Sikanshui, $500 \mathrm{~m}$, secondary forest, 22.ii.2013, Y. R. Huang (NTU); 1 9 , New Taipei City, Xindian Dist.,

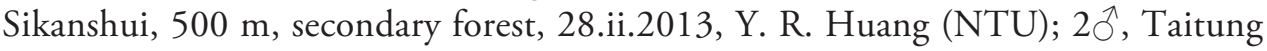
County, Haiduan Township, Xiama, 790 m, secondary forest, 30.v.2013, S. T. Yang (NTU). 


\section{Subfamily POLLENIINAE}

Dexopollenia Townsend, 1917

\section{Dexopollenia flava (Aldrich, 1930)}

Materials. 10, Taichung, Pilushi, 2,200 m, 22-23.v.1988, R. Davidson, C. Young \& J. Rawlins (CMNH); 10, Fanshan, 1,650 m, 5.xi.1985, M. Iwasa (IDD).

\section{Dexopollenia luteola (Villeneuve, 1927)}

Note. See to James (1977: 532).

\section{*Dexopollenia maculata Villeneuve, 1933}

Materials. 1ðึ, Nantou County, Hohuan-shan, Tayulin, 2700 m, 23.vii.1985, S. Shinonaga (NSMT).

\section{Subfamily CHRYSOMYINAE \\ Tribe Chrysomyini \\ Achoetandrus Bezzi, 1927}

\section{Achoetandrus rufifacies (Macquart, 1843)}

Materials. Orchid Is.: 28 09 59, Taitung County, Lanyu Township, Hongtou, Weather Station, 231 m, tropical rainforest, 01.vi.2013, S. T. Yang (NTU); Orchid Is.: 1ð̊ 9 , Taitung County, Lanyu Township, Hongtou, 15 m, seashore, 01.vi.2013, S. T. Yang (NTU); Orchid Is.: $8 \hat{\jmath} 9$ ㅇ, Taitung County, Lanyu Township, Longmen Harbor, 5 m, seashore, 01.vi.2013, S. T. Yang (NTU); Orchid Is.: 4ત 1 9 , Taitung County, Lanyu Township, Dongqing, Qingrendong, $18 \mathrm{~m}$, seashore, 01.vi.2013, S. T. Yang (NTU); Orchid Is.: 19, Taitung County, Lanyu Township, Zhong'ai Bridge, $53 \mathrm{~m}$, tropical rainforest, 01.vi.2013, S. T. Yang (NTU); $10 \AA 35$, Chiayi County, Alishan Town-

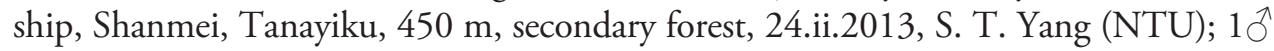
2+, Kaohsiung City, Jiaxian Dist., Jiaxian, 278 m, secondary forest, 12.v.2013, S. T. Yang (NTU); 4018 , Taitung County, Haiduan Township, Xiama, $790 \mathrm{~m}$, secondary forest, 30.v.2013, S. T. Yang (NTU); $3 \jmath^{\Uparrow}$ \% , Taitung County, Haiduan Township,

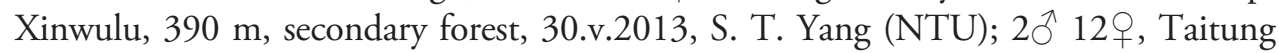
County, Luye Township, Ruiyuan, 198 m, farmland, 30.v.2013, S. T. Yang (NTU); 1§. Taitung County, Beinan Township, Jhihben, 209 m, secondary forest, 15.ii.2013, S. T. Yang (NTU); 4우, Taitung County, Dawu Township, Dawu, 85 m, secondary 
forest, 18.iv.2013, S. T. Yang (NTU); $7 ð$ 25요 Hualien County, Xincheng Township, Qixingtan, Sihba Height, 41 m, grassland, 09.v.2013, S. T. Yang (NTU); 2 , Hualien County, Xincheng Township, Qixingtan, 14 m, seashore, 09.v.2013, S. T. Yang (NTU); 1 , , Hualien County, Xiulin Township, Fushi, Changuang Temple, 120 m, monsoon rainforest, 09.v.2013, S. T. Yang (NTU); 2q, Hualien County, Shoufeng Township, Pinghe, 41 m, plain, 16.ii.2013, S. T. Yang (NTU); 19, Hualien County, Yuli Township, 133 m, plain, 16.ii.2013, S. T. Yang (NTU); 4へ 13우, Pingtung County, Sangdimen Township, Sandi Village, $381 \mathrm{~m}$, secondary forest, 2.iv.2013, S. T. Yang (NTU); 2へ, Pingtung County, Manzhou Township, Qikong Waterfall, 40-125 m, secondary forest, 24.i.2013, S. T. Yang (NTU); Liuqiu Is.: $2 \delta^{\lambda} 21$, P Pingtung County, Liuqiu Township, Geban Bay, 10 m, seashore, 04.v.2013, S. T. Yang (NTU); Liuqiu

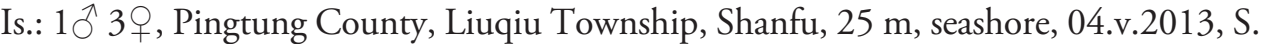
T. Yang (NTU); 19, Pingtung County, Shizi Township, Shuangliu, $352 \mathrm{~m}$, secondary forest, 19.v.2013, S. T. Yang (NTU); 2 , , Taipei City, Da'an Dist., Fuzhoushan Park, $71 \mathrm{~m}$, secondary forest, 17.iii.2013, S. T. Yang (NTU); 7ㅇ, Taipei City, Da'an Dist., Fuzhoushan Park, 100 m, secondary forest, 17.iii.2013, S. T. Yang (NTU); $8 \hat{\jmath} 20$, Taipei City, Da'an Dist., NTU Agricultural Entomology Building, 12 m, orchard; eggs collected, 05.ii.2013 eclosion, 19.viii.2009, S. T. Yang (NTU); 1, Taipei City, Wenshan Dist., Saint's Alp, 144 m, secondary forest, 21.xii.2012, S. T. Yang (NTU); 3우 Taipei City, Neihu Dist., Daluntou Mt., 352 m, secondary forest, 19.v.2013, S. T. Yang (NTU); 1 , , Yilan County, Toucheng Township, Beiguan, $34 \mathrm{~m}$, seashore, 04.iv.2013, S. T. Yang (NTU); 1 9 , Kaohsiung, Shanping, 640 m, 21-30.iv.1988, C.

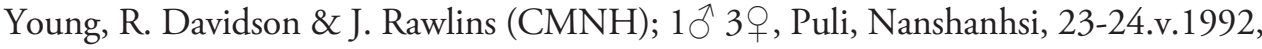

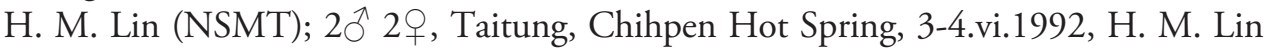
(NSMT); $1 \overbrace{}^{\Uparrow} 4$ 우, Fushan B. G., 600 m, 3-6.v.2006, H. Kurahashi (NSMT); 101 우, Chihpen, 15.XI.1985, K. Kanmiya (NSMT); $1 \overbrace{}^{\Uparrow} 5$ q , Antung, 12.XI.1985, K. Kanmiya (NSMT); 2q, Tainan, Kuantzling, 26.v.1992, R. Kano (NSMT); 1, Nanshanchi, 1.v.2006, H. Kurahashi (NSMT); 5, Liuknei, 12.VII.1985, S. Shinonaga (NSMT); $1 \widehat{\jmath} 3$ ㅇ, Kenting Park, 18-19.XI.1985, K. Kanmiya, R. Kano \& H. M. Lin (NSMT);

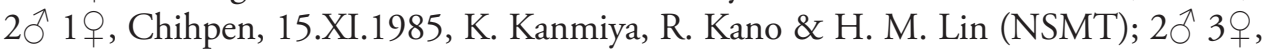
Santimen, 13.VII.1985, S. Shinonaga (NSMT); 1언, Kuan-zu-ling, 250m, 6.IV.1965, R. Kano (NSMT); 19, Chiai, 7.IV.1965, C. M. Yoshimoto \& B. D. Parkins (NSMT); $2 \widehat{\jmath} 8$, Antung, 12.XI.1985, K. Kanmiya, R. Kano \& H. M. Lin (NSMT).

\section{Achoetandrus villeneuvi (Patton, 1922)}

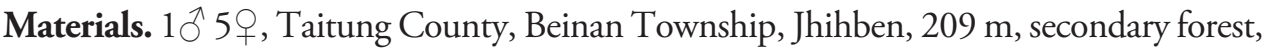
15.ii.2013, S. T. Yang (NTU); 2 + , Hualien County, Xiulin Township, Fushi, Changuang Temple, $120 \mathrm{~m}$, monsoon rainforest,09.v.2013, S. T. Yang (NTU); 1q, Hualien County, Wanrong Township, Wanrong, $1000 \mathrm{~m}$, secondary forest, 08.iv.2013, W. H. Lin (NTU); 29, Chiayi County, Alishan Township, Shanmei, Tanayiku, $450 \mathrm{~m}$, secondary forest, 24.ii.2013, S. T. Yang (NTU); 49, Taitung County, Haiduan Township, 
Xiama, 790 m, secondary forest, 30.v.2013, S. T. Yang (NTU); 29, Taipei City, Neihu Dist., Daluntou Mt., 352 m, secondary forest, 19.v.2013, S. T. Yang (NTU); 2ठ, Luchan, 1,000 m, 24-25.vii.1985, S. Shinonaga (NSMT); 6ð 29, Fushan B. G., 600 m, 3-6.v.2006, H. Kurahashi (NSMT); $2 \widehat{\jmath} 4$, Kaohsiung, Shanping, 640 m, 21-30. iv.1988, C. Young, R. Davidson \& J. Rawlins (CMNH); 1§̋, Taoyuen, Paling, 9-11.

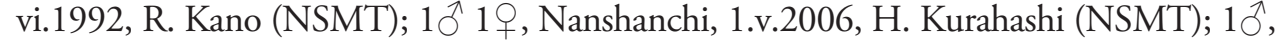
Ten-chih, 23-04-03 N, 120-45-13 E, 1,550 m, 23.viii.1996, C. W. Young (CMNH).

\section{Ceylonomyia Fan, 1965}

\section{*Ceylonomyia nigripes (Aubertin, 1932)}

Materials. Orchid Is.: $10 \widehat{\jmath} 169$, Taitung County, Lanyu Township, Hongtou, Weather Station, $231 \mathrm{~m}$, tropical rainforest, 01.vi.2013, S. T. Yang (NTU); Orchid Is.: $1 \hat{\jmath}$ $1 q$, Taitung County, Lanyu Township, Longmen Harbor, 5 m, seashore, 01.vi.2013, S. T. Yang (NTU); Orchid Is.: 1온, Taitung County, Lanyu Township, Hongtou, 15 m, seashore, 01.vi.2013, S. T. Yang (NTU); 1 , , Hualien County, Xiulin Township, Fushi, Changuang Temple, 120 m, monsoon rainforest, 09.v.2013, S. T. Yang (NTU); 1 옹 Kaohsiung City, Jiaxian Dist., Jiaxian, 278 m, secondary forest, 12.v.2013, S. T.

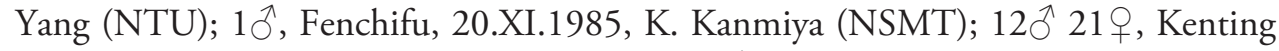
Park, 18-19.XI.1985, K. Kanmiya (NSMT); 2ð̂, Antung, 12.XI.1985, K. Kanmiya

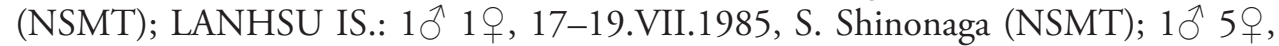
Santimen, 13.VII.1985, S. Shinonaga (NSMT); $10 \lesssim 3$ 3, Liuknei, 12.VII.1985, S. Shinonaga (NSMT); 1 , , Kenting Park, 18-19.xi.1985, K. Kanmiya (NSMT); 3웅, Fushan B. G., 600 m, 3-6.v.2006, H. Kurahashi (NSMT); 1ð̋, Kaohsiung, Shanping, 640 m, 21-30.iv.1988, C. Young, R. Davidson \& J. Rawlins (CMNH); 1잉 Juisui, 10.XI.1985, K. Kanmiya, R. Kano \& H. M. Lin (NSMT); 1 q , Juisui, 11.XI.1985, K. Kanmiya (NSMT); 3ðึ, Kenting Park, 18-19.XI.1985, K. Kanmiya, R. Kano \& H. M. Lin (NSMT); 19, Kenting Park, 18-19.xi.1985, K. Kanmiya (NSMT).

\section{Chrysomya Robineau-Desvoidy, 1830}

\section{Chrysomya bezziana Villeneuve, 1914}

Note. See to Fan (1992: 544).

\section{Chrysomya megacephala (Fabricius, 1794)}

Materials. $65 \hat{\jmath}$ 87, Hualien County, Xincheng Township, Qixingtan, Sihba Height, 41 m, grassland, 09.v.2013, S. T. Yang (NTU); $4 \hat{\jmath}$ 6ㅇ, Hualien County, 
Xincheng Township, Qixingtan, 14 m, seashore, 09.v.2013, S. T. Yang (NTU); 1 , Hualien County, Xiulin Township, Taroko, 81 m, canyon, 09.v.2013, S. T. Yang (NTU); 1엉 Hualien County, Guangfu Township, 143 m, plain,16.ii.2013, S. T.

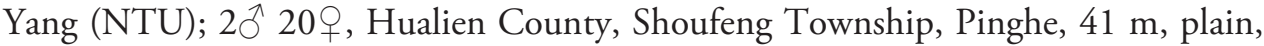
16.ii.2013, S. T. Yang (NTU); $2 \widehat{\jmath} 5$, Taipei City, Neihu Dist., Daluntou Mt., $352 \mathrm{~m}$, secondary forest, 19.v.2013, S. T. Yang (NTU); $10^{\widehat{O}} 19$ 우, Taipei City, Da'an Dist., Fuzhoushan Park, $71 \mathrm{~m}$, secondary forest, 17.iii.2013, S. T. Yang (NTU); $1 \delta^{\lambda}$ 1우, Taipei City, Da'an Dist., NTU Agricultural Entomology Building, 12 m, orchard, 22.i.2013, S. T. Yang (NTU); 19, New Taipei City, Shimen Dist., Linshan Cape, 4 m, seashore, 21.xii.2012, S. T. Yang (NTU); 12으, New Taipei City, Shimen Dist., Linshan Cape, 4 m, seashore, 29.xii.2012, S. T. Yang (NTU); 10, New Taipei City, Wulai Dist., Hsiaoi Village, Tonghou, 233 m, riverside, 27.xii.2012, S. T. Yang (NTU); 1 , , New Taipei City, Xindian Dist., Zhitan Dam, 57 m, riverside, 27.xii.2012, S. T. Yang (NTU); $1 \widehat{\jmath} 20$, Taitung County, Luye Township, Ruiyuan, 198 m, farmland, 30.v.2013, S. T. Yang (NTU); 1ㅇ, Taitung County, Beinan Township, Jhihben, $209 \mathrm{~m}$, secondary forest, 15.ii.2013, S. T. Yang (NTU); $3 \hat{\jmath} 31$, Taitung County, Dawu Township, Dawu, 85 m, secondary forest, 18.iv.2013, S. T. Yang (NTU); $7 \jmath^{\Uparrow}+$, Taitung County, Haiduan Township, Xiama, 790 m, secondary forest, 30.v.2013, S. T. Yang (NTU); 1 $\hat{\jmath}$, Taitung County, Haiduan Township,

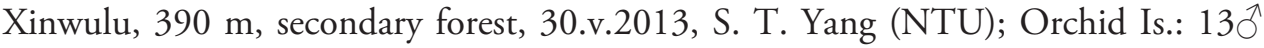
59, Taitung County, Lanyu Township, Hongtou, Weather Station, $231 \mathrm{~m}$, tropical rainforest, 01.vi.2013, S. T. Yang (NTU); Orchid Is.: 30 18우, Taitung County, Lanyu Township, Hongtou, 15 m, seashore, 01.vi.2013, S. T. Yang (NTU); Orchid Is.: 2 , , Taitung County, Lanyu Township, Yeyou, $8 \mathrm{~m}$, seashore, 31.v.2013, S. T. Yang (NTU); Orchid Is.: 2우, Taitung County, Lanyu Township, Longmen Harbor, 5 m, seashore, 01.vi.2013, S. T. Yang (NTU); Mazu, Beigan Is.: 4ภ 2 County, Beigan Township, 100 m, seashore, 12.v.2013, Y. C. Yu (NTU); Liuqiu Is.: $6{ }^{\Uparrow} 33$, Pingtung County, Liuqiu Township, Shanfu, 25 m, seashore, 04.v.2013, S. T. Yang (NTU); Liuqiu Is.: $6{ }^{\lambda} 5$, , Pingtung County, Liuqiu Township, Shanfu, 25 m, seashore; eggs collected, 17.v.2013 eclosion, 04.v.2013, S. T. Yang (NTU); Liuqiu Is.: $6 \hat{\jmath} 7$, , Pingtung County, Liuqiu Township, Dafu Fishing Port, $8 \mathrm{~m}$, seashore; eggs collected, 17.v.2013 eclosion, 04.v.2013, S. T. Yang (NTU); Liuqiu Is.: 10๊, Pingtung County, Liuqiu Township, Dafu Fishing Port, 8 m, seashore, 04.v.2013, S. T. Yang (NTU); Liuqiu Is.: $1 \widehat{\delta}^{\hat{\gamma}} 4$, , Pingtung County, Liuqiu Township, White Lighthouse, $82 \mathrm{~m}$, secondary forest, 04.v.2013, S. T. Yang (NTU); Liuqiu Is.: $2 \widehat{ }$ 115우, Pingtung County, Liuqiu Township, Geban Bay, 10 m, seashore, 04.v.2013, S.

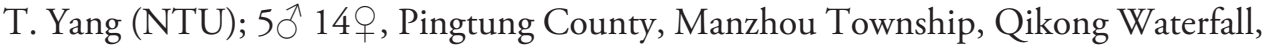

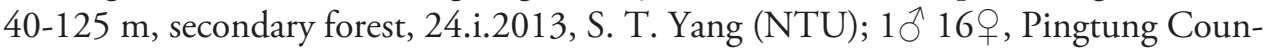
ty, Sangdimen Township, Sandi Village, $381 \mathrm{~m}$, secondary forest, 02.iv.2013, S. T. Yang (NTU); $3{ }^{\wedge} 3 q$, Kaohsiung City, Jiaxian Dist., Jiaxian, 278 m, secondary forest,

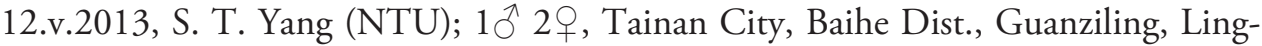
ding Park, 322 m, secondary forest, 21.iii.2013, S. T. Yang (NTU); $1 \overbrace{}^{\Uparrow} 2$, Chiayi County, Alishan Township, Shanmei, Tanayiku, 450 m, secondary forest, 24.ii.2013, 
S. T. Yang (NTU); $1 \overbrace{}^{\Uparrow} 3$, Yilan County, Toucheng Township, Beiguan, $34 \mathrm{~m}$, seashore, 04.iv.2013, S. T. Yang (NTU); 5, Fenchifu, 20.XI.1985, K. Kanmiya (NSMT); $2 \hat{\jmath}$, Santimen, 13.VII.1985, S. Shinonaga (NSMT); 10, Hori, 2.VII.1965, T. Shirozu (NSMT); $1 \overbrace{}^{\Uparrow} 1$, Honbukei, 2.V.1965, T. Shirozu (NSMT); 1, Chuch'i, 120m, 13.IV.1965, R. Kano (NSMT); 40 5우 Chichiwanchi, Huanshan, 5-6. XI.1985, K. Kanmiya (NSMT); 1ㅇ, Chihpen, 15.XI.1985, K. Kanmiya (NSMT); 1q, San Palin, 1,100m, 25.X.1985, R. Kano (NSMT); $2 \overbrace{}^{\Uparrow}$ \% , Antung, 12.XI.1985, K. Kanmiya (NSMT); 20, Yangmin-shan, 28.X.1985, K. Kanmiya (NSMT); 2 , Juisui, 10.XI.1985, K. Kanmiya (NSMT); LAN HSU IS.: 10, Yehyin, 7.VII.1971, K. Mizusawa (NSMT); 1 9 , Wulai, 4.VII.1985, S. Shinonaga (NSMT); LANHSU IS.: $4 \widehat{0}$ 6ㅇ, 17-19.VII.1985, S. Shinonaga (NSMT); 20 2 9 , Liuknei, 12.VII.1985, S. Shinonaga (NSMT); $2 \AA 2$, Fenchifu, 1,400m, 8.VII.1985, S. Shinonaga (NSMT); $3 \hat{\jmath}$, Kenting Park, 15.VII.1985, S. Shinonaga (NSMT); 10 , Taipei, 30.III.1965, R. Kano (NSMT); 2へ, Hohuan-sahn, Tsuifeng, 2,400m, 23-24.VII.1985, S. Shinonaga (NSMT); $1 \hat{\jmath} 3$, Antung, 12.XI.1985, K. Kanmiya (NSMT); $2 \hat{}$, Kwantyling, 11.VII.1985, S. Shinonaga (NSMT); 19, Taihoku, 18.vii.1927, F. C. Hadden (BPBM); 2q, Taoyuen, Paling, 9-11.vi.1992, R. Kano (NSMT); 39 , Kenting Park, 1-2.vi.1992, H. M. Lin (NSMT); 10 2ㅇ, Chung-Hsien University, Huei-sun Forest, 21.v.1992, R. Kano (NSMT); 60 18, Ten-chih, 23-04-03 N, 120-45-13 E,

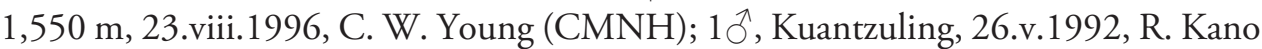
(NSMT); 5 12우, Kaohsiung, Shanping, 640 m, 21-30.iv.1988, C. Young, R. Davidson \& J. Rawlins (CMNH); 19, Taihoku, 18.vii.1927, F. C. Hadden (BPBM);

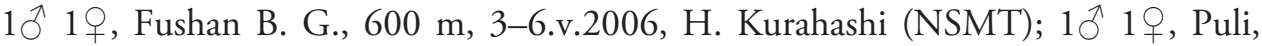
Nanshahsi, 23-24.v.1992, H. M. Lin (NSMT).

\section{Chrysomya pinguis (Walker, 1858)}

Materials. $1 \widehat{\delta} 1$, Nantou County, Ren'ai Township, Aowanda, 18.v.2013, K. Harusawa (PCKHa); 1ㅇ, Nantou County, Ren'ai Township, Gaofeng, Guantou Mt. (Northeast), 20.v.2013, K. Harusawa (PCKHa); 41仓̂ 119우, Taitung County, Beinan Township, Jhihben, 209 m, secondary forest, 15.ii.2013, S. T. Yang (NTU); $2 \widehat{1} 18$, Taitung County, Haiduan Township, Xiama, $790 \mathrm{~m}$, secondary forest, 30.v.2013, S. T. Yang (NTU); 1q, New Taipei City, Gongliao Dist., Santiago Cape, 97 m, bushes, 28.ii.2013, S. T. Yang (NTU); 10 7우, Taipei City, Da'an Dist., Fuzhoushan Park, 71 m, secondary forest, 17.iii.2013, S. T. Yang (NTU); 1우, Yilan County, Toucheng Township, Beiguan, 34 m, seashore, 04.iv.2013, S. T. Yang (NTU); 1우, Hualien County, Xiulin Township, Taroko, $81 \mathrm{~m}$, canyon, 09.v.2013, S. T. Yang (NTU); 3 , , Hualien County, Xiulin Township, Fushi, Changuang Temple, $120 \mathrm{~m}$, monsoon rainforest, 09.v.2013, S. T. Yang (NTU); Mazu,

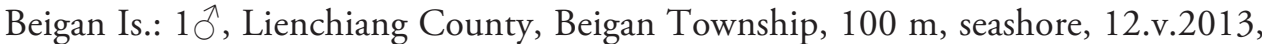
Y. C. Yu (NTU); 3 , New Taipei City, Xindian Dist., Qingtan, Sishifen, 419 m,

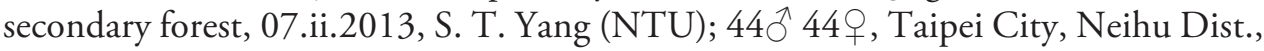


Daluntou Mt., 352 m, secondary forest, 19.v.2013, S. T. Yang (NTU); 10, Pingtung County, Manzhou Township, Qikong Waterfall, 40-125 m, secondary forest, 24.i.2013, S. T. Yang (NTU); 4ㅇ, Pingtung County, Shizi Township, Shuangliu, 189-300 m, secondary forest, 11.v.2013, S. T. Yang (NTU); 27 $\lesssim 249$, Nantou County, Ren'ai Township, Meifeng Farm, 2100 m, secondary forest; eggs collected, 23.i.2013 eclosion, 28.viii.2011, Y. J. Liu (NTU); 90 19中, Nantou County, Lugu Township, Xitou, 1156 m, secondary forest, 08.iii.2013, S. T. Yang (NTU);

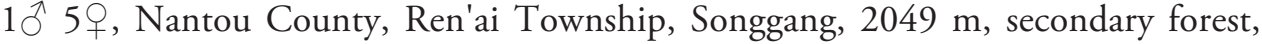
16.iv.2013, S. T. Yang (NTU); 2 , New Taipei City, Wugu Dist., Guanyin Mt., Yinghan Peak, 359-611 m, secondary forest, 30.iv.2013, S. T. Yang (NTU); 40 9, Taichung City, Heping Dist., Huanshan Tribe, Ssuchiehlan Stream, 1832 m, riverbed; larvae collected, 09.ii.2013 eclosion, 26.i.2013, S. T. Yang (NTU); $39 \AA 94$, New Taipei City, Wulai Dist., Xinxian Village, 219 m, riverside, 16.iii.2013, S. T. Yang (NTU); $3{ }^{\lambda}$ 16우, Taipei City, Wenshan Dist., Saint's Alp, 144 m, secondary forest, 21.xii.2012, S. T. Yang (NTU); $5 \AA 1$, , Yilan County, Toucheng Township, Yingzi Mt., 936 m, bush, 27.v.2013, S. T. Yang (NTU); 4q, Chiayi County, Alishan Township, Shanmei, Tanayiku, $450 \mathrm{~m}$, secondary forest, 24.ii.2013, S. T. Yang (NTU); 19, New Taipei City, Shimen Dist., Linshan Cape, 20 m, seashore, 21.xii.2012, S. T. Yang (NTU); $7 ð 12$, New Taipei City, Wulai Dist., Hsiaoi Village, Tonghou, 233 m, riverside, 27.xii.2012, S. T. Yang (NTU); 4우, New Taipei City, Xindian Dist., Zhitan Dam, 57 m, riverside, 27.xii.2012, S. T. Yang (NTU); 1ㅇ, New Taipei City, Wulai Dist., Zhongzhi, 109 m, riverside, 27.xii.2012, S. T. Yang (NTU); $2 \hat{0}$ 6, New Taipei City, Ruifang Dist., Jinguashih, Chahu Mt., 343 m, bush, 01.ii.2013, S. T. Yang (NTU); 10 11우, New Taipei City, Ruifang Dist., Jinguashih, Chahu Mt., $416 \mathrm{~m}$, bush, 01.ii.2013, S. T. Yang (NTU); 1우, New Taipei City, Ruifang Dist., Jinguashih, 360 m, house, 05.ii.2013, T. H. Wu (NTU); $1 \hat{\jmath}$, San Palin, 1,100m, 25.X.1985, R. Kano (NSMT); $3 \hat{\jmath} 2$ 으, Lalashan, Taoyuen, 12.vi.1992, H. M. Lin (NSMT); 2 , Chihpen, 15.XI.1985, K. Kanmiya, R. Kano \& H. M. Lin (NSMT); 6へ 5, Huanshan, Chichiawanchi, 5-6.XI.1985, K. Kanmiya, R. Kano \& H. M. Lin (NSMT); 10, Lafu, 350m, 27.X.1985, R. Kano (NSMT); 2ð 7을 Fenchifu, 20.XI.1985, K. Kanmiya, R. Kano \& H. M. Lin (NSMT); $2{ }^{\Uparrow}$ 69, Lala shan, 1,400-1,600m, 25-26.X.1985, R. Kano \& H. M. Lin (NSMT); 2へ, Antung, 12.XI.1985, K. Kanmiya, R. Kano \& H. M. Lin (NSMT); $3{ }^{\lambda} 2$ 으, Hohuan-shan, Yuankang, 2,700m, 23.VII.1985, S. Shinonaga (NSMT); 2ㅇ, Chiapaotai, 4.XI.1985, K. Kanmiya, R. Kano \& H. M. Lin (NSMT); $1 \hat{\jmath} 1$, Mt. Yang-ming Shan, 450m, 28.III.1965, R. Kano (NSMT); $1 \widehat{o}^{\wedge} 1$ \% , Lushan, 1,000m, 24-25.VII.1985, S. Shinonaga (NSMT); 1우, Taichung, Pilushi, 2,200 m, 22-23.v.1988, R. Davidson, C. Young \& J. Rawlins (CMNH); 4ㅇ, Taitung, Chihpen Hot Spring, 3-4.vi.1992, H. M. Lin (NSMT); 4仓 3ㅇ, Taoyuen, Paling, 9-11. vi.1992, R. Kano (NSMT); 8 4우, Puli, Nanshanhsi, 23-24.v.1992, N. M. Lin (NSMT); $10^{\Uparrow} 5$, , Chung-Hsien University, Huei-sun Forest, 21.v.1992, R. Kano (NSMT); $1 \hat{\jmath} 19$, Alishan, 2,400m, 9-10.VII.1985, S. Shinonaga (NSMT); 4ภ 4ㅇ, 
Mt. Alishan, 28-29.v.1992, R. Kano (NSMT); 22ð 33우, Kaohsiung, Shanping, 640 m, 21-30.iv.1988, C. Young, R. Davidson \& J. Rawlins (CMNH); 20̂, Wulai, Taipei, 15.vi.1992, R. Kano (NSMT); 10 , Anmashan, 2,230 m, 30.iv.-4.v.1990, A. Smetana $(\mathrm{CMNH}) ; 3 \hat{\jmath} 7$, Nanshanchi, 1.v.2006, H. Kurahashi (NSMT); $3 \hat{\jmath}$ 7 , , nr Huanshan, 2.v.2006, H. Kurahashi (NSMT); $2 \hat{\jmath} 3$ ㅇ, Ten-chih, 23-04-03 N, 120-45-13 E, 1,550 m, 23.viii.1996, C. W. Young (CMNH); 17 §̂ 21 q, Fushan B. G., 600 m, 3-6.v.2006, H. Kurahashi (NSMT); $18 \hat{\jmath} 4$, , Hohuan-sahn, Tsuifeng, 2,400m, 23-24.VII.1985, S. Shinonaga (NSMT).

\section{Tribe Phormiini}

Protocalliphora Hough, 1899

Protocalliphora sp.

Materials. 1 9 , Mt. Alishan, 2,400 m, 9-10.vii.1985, S. Shinonaga (NSMT). [See to Kurahashi (2000: 27)]

\section{Subfamily RHINIINAE}

\section{Tribe Rhiniini}

Idiella Brauer \& Bergenstamm, 1889

${ }^{*}$ Idiella divisa (Walker, 1861)

Materials. 4ð 5q, Chihpen, 15.xi.1985, K. Kanmiya (NSMT); 1ð, Shui-tao, 220 m, 15.iv.1915, S. Ueno (NSMT); 1 9 , Fenchifu, 20.xi.1965, K. Kanmiya (NSMT).

\section{Idiella euidielloides Senior-White, 1923}

Materials. 20, Nantou County, Ren'ai Township, Aowanda, 18.v.2013, K. Harusawa (PCKHa); $2 \hat{\jmath} 1$, , Nantou County, Ren'ai Township, Gaofeng, Guantou Mt. (Northeast), 20.v.2013, K. Harusawa (PCKHa); 19, Chihpen, 15.xi.1985, K. Kanmiya (NSMT); 10, Chung-Hsien University, Huei-sun Forest, 21.v.1992, R. Kano (NSMT); 20 4, Taoyuen, Paling, 9-11.vi.1992, R. Kano (NSMT); 39 , Nanshanhsi, nr Puli, 23-24.v.1992, R. Kano \& H. M. Lin (NSMT); 1 9 , Meifeng, 2, 130 m, 10-17. vii.1993, A. Smetana (CMNH); 1으, Kaohsiung, Ten-chih, 23.04'03"N, 120.45'13"E, 1,550 m, 23.viii.1996, C. W. Young (CMNH); 19, Chihpen, 15.xi.1985, K. Kanmiya (NSMT); $80^{\hat{3}} 3$ \% , Fushan B. G., 600 m, 3-6.v.2006, H. Kurahashi (NSMT); $10^{\Uparrow}$ 19, Chihpen, 15.xi.1985, K. Kanmiya (NSMT); 19, Hsitou, 1,000 m, 1.v.2006, H. Kurahashi (NSMT); 3 + , Nanshanchi, 1.v.2006, H. Kurahashi (NSMT). 


\section{Idiella mandarina (Wiedemann, 1830)}

Materials. 1ठ, Kenting-kung-yuan, 3.iv.1965, R. Kano (NSMT).

\section{Rhinia Robineau-Desvoidy, 1830}

\section{Rhinia apicalis (Wiedemann, 1830)}

Materials. 1q, Nantou County, Ren'ai Township, Lushan, 1000 m, 10.x.2010, S. T. Yang (NTU); 1ð, Hohuan-shan, Kunyan, 2,700 m, 23.vii.1985, S. Shinonaga (NSMT); 2ㅇ, Hohuan-shan, Tsuifeng, 2,400 m, 23-24.vii.1985, S. Shinonaga (NSMT); 1으, Lushan, 1,000 m, 24-25.vii.1985, S. Shinonaga (NSMT); 1 đ 4ㅇ, Huanshan, Chichiawanchi, 6.xii.1985, K. Kanmiya (NSMT); 10, Tsuifeng-Shunkan, 24.vii.1985, H. Shima (NSMT); 19, Nanshanhsi nr Puli, 23-24.v.1992, R. Kano (NSMT); 10̄, Hohuan-shan, Tsuifeng-Shunkan, 24.vii.1985, H. Shima (NSMT); 10 , Tsuifeng-Shunkan, 24.vii.1985, H. Shima (NSMT).

\section{Rhinia sauteri Peris, 1951}

Note. See to James (1977: 553).

\section{Stomorbina Rondani, 1861}

\section{Stomorbina discolor (Fabricius, 1794)}

Materials. 1, Pingtung County, Manzhou Township, Qikong Waterfall, 40-125 m, secondary forest, 24.i.2013, S. T. Yang (NTU); 10, Kentin, 1.II.1972, K. Matsuki (NSMT); 10̂, Kentin Park (Kontei Park), 13.viii.1980, K. Hara (NSMT); 2 , Antung, 12.x.1985, K. Kanmiya (NSMT); 10̄, Juisui, 10.xi.1985, K. Kanmiya (NSMT); 1우, Oluanpi (Galanpi), 13.viii.1980, K. Hara (NSMT); 10̋, nr Alishan, Shanmei, 1,300 m, 29.iv.2006, H. Kurahashi (NSMT); 10 , Ch'-hsin-liao, 15.iv.1965, S. Ueno (NSMT); 10, Lushan, 1,000 m, 24-25.vii.1985, S. Shinonaga (NSMT).

\section{Stomorbina lunata (Fabricius, 1805)}

Note. See to Hennig (1941: 181). 
${ }^{*}$ Stomorbina obsoleta (Wiedemann, 1830)

Materials. 1 , Lushan, 1,000 m, 24-25.vii.1985, S. Shinonaga (NSMT); 1 9 , Fen-ch'i-hu, 12.iv.1965, R. Kano (NSMT); 10̄, Hotso (Roshan), 30.ix.1965, K. Kaneko (NSMT).

\section{Stomorhina veterana Villeneuve, 1927}

Materials. 1ð, Yingfeng (Gokansan), 19.viii.1980, K. Hara (NSMT); 1ㅇ, Alishan-Yushan, 2,600-2,700 m, 31.x.1985, M. Iwasa (NSMT); 1 9 , Hohuan-shan, Tsuifeng, 2,400 m, 2324.vii.1985, S. Shinonaga (NSMT); 19, Hohuan-shan, Kunyan, 2,700 m, 23.vii.1985, S. Shinonaga (NSMT); 7ᄋ, Meifeng, 2,130 m, 10-17.vii.1993, A. Smetana (CMNH); 10, Fenchihu, 4.iv.1965, R. Kano (NSMT); 19, Ten-chin, 23.04'03"N 120.45'13"E, 1,550 m, 23.viii.1996, C. W. Young (CMNH); 1ㅇ, Tattaka, 10.iv.1965, T. Saigusa (NSMT); 10․, Mt. Yui-shan, 2,700-3,500 m, 6-7.vii.1985, S. Shinonaga (NSMT); 19, Mt. Yuishan, 2,700-3,500m, 6-7.VII.1985, S. Shinonaga (NSMT); 19, Hohuan-shan, Yuankang, 2,700m, 23.VII.1985, S. Shinonaga (NSMT); 12요 Hohuan-shan, Tsuifeng, 2,400m, 23-24.VII.1985, S. Shinonaga (NSMT); 10, Fenchihu, 12.IV.1965, R. Kano (NSMT); $1 \hat{\jmath}$ 1우, Tatachia-anpu, 31.x.1985, K. Kanmiya (NSMT); 10, Tatachiaanpu-Paiyunshanchuan, 6.vii.1985, H. Shima (NSMT); 1우, Alishan-Yushan, 2,600-2,700 m, 31.x.1985, M. Iwasa (NSMT); 1, Alishan-Yushan, 2,600-2,700 m, 31.x.1985, M. Iwasa (NSMT).

\section{Stomorbina xanthogaster (Wiedemann, 1820)}

Materials. $9 \widehat{\jmath}$ 4, New Taipei City, Shimen Dist., Linshan Cape, 20 m, seashore, 29.xii.2012, S. T. Yang (NTU).

\section{Tribe Cosminini}

Borbororhinia Townsend, 1917

Borbororbinia bivittata (Walker, 1857)

Note. See to James (1977: 544).

\section{Isomyia Walker, 1860}

\section{${ }^{*}$ Isomyia delectans (Walker, 1860)}

Materials. 1, Yilan County, Toucheng Township, Yingzi Mt., 936 m, bush, 27.v.2013, S. T. Yang (NTU). 


\section{Isomyia electa (Villeneuve, 1927)}

Materials. $1 \widehat{\jmath}$, New Taipei City, Wulai Dist., Wulai, $500 \mathrm{~m}$, secondary forest, 20.vi.2011, Y. C. Yu (NTU); $2 \widehat{\jmath} 8$ क , Fushan B. G., 600 m, 3-6.v.2006, H. Kurahashi (NSMT).

\section{*Isomyia oestracea (Séguy, 1934)}

Materials. 1ㅇ, Taitung County, Haiduan Township, Xiama, 790 m, secondary forest, 30.v.2013, S. T. Yang (NTU); 4ð , Fushan B. G., 600 m, 3-6.v.2006, H. Kurahashi (NSMT); 1 9 , Fushan Botanical Garden, 750 m, 28.vi.2010, K. Harusawa (PCKHa).

\section{*Isomyia pseudolucilia (Malloch, 1928)}

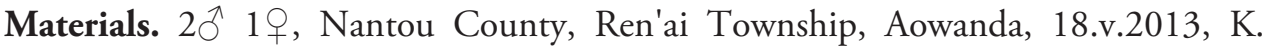
Harusawa (PCKHa); $1 \overbrace{}^{\lambda} 1+$, New Taipei City, Wugu Dist., Guanyin Mt., Yinghan Peak, 359-611 m, secondary forest, 30.iv.2013, S. T. Yang (NTU); 3 ㅇ, Taipei City, Neihu Dist., Daluntou Mt., 352 m, secondary forest, 19.v.2013, S. T. Yang (NTU); 2ㅇ, Liuknei, 12.vii.1985, S. Shinonaga (NSMT); 17ð 37우, Fushan B. G., 600 m, 3-6.v.2006, H. Kurahashi (NSMT).

\section{Isomyia tibialis (Villeneuve, 1927)}

Materials. 10, Kukan, 3.xi.1985, K. Kanmiya (NSMT); 1q, Tsuifen-Shunkan, 24.vii.1985, H. Shima (NSMT); 1 9 , Paling, Taoyuen, 9-11.vi.1992, R. Kano (NSMT).

Isomyia viridaurea (Wiedemann, 1819)

Note. See to James (1977: 551).

Rhyncomya Robineau-Desvoidy, 1830

Rhyncomya notata (van Der Wulp, 1880)

Note. See to Fan (1992: 565). 
Rhyncomya setipyga Villeneuve, 1927

Materials. $2 \jmath^{\Uparrow} 1$, New Taipei City, Shimen Dist., Linshan Cape, 20 m, seashore, 29.xii.2012, S. T. Yang (NTU).

Strongyloneura Bigot, 1886

*Strongyloneura diploura Fang \& Fan, 1984

Materials. Kinmen Is.: 2ð 2q, Shiahsintsuoh, 8.viii.1993, C. L. Chung (NSMT).

Strongyloneura prasina Bigot, 1886

Note. See to James (1977: 555).

*Strongyloneura prolata (Walker, 1860)

Materials. 10 , Kuantzuling, 26.v.1992, R. Kano (NSMT).

Sumatria Malloch, 1926

${ }^{*}$ Sumatria chiekoae Kurahashi \& Tumrasvin, 1992

Materials. 10, Lenai, 1,000 m, 23.vii.1985, S. Shinonaga (NSMT); 19, Lala Shan, 1,400 m, 25.x.1985, R. Kano (NSMT); 10, Lenai, 1,000 m, 23.vii.1985, S. Shinonaga (NSMT); 2q, Taoyuen, Paling, 9-11.vi.1992, R. Kano (NSMT).

\section{Sumatria flava (Villeneuve, 1927)}

Materials. 1 , , Hsitou, 1,000 m, 1.v.2006, H. Kurahashi (NSMT); 1 , , Hsitou, 1,000 m, 1.v.2006, H. Kurahashi (NSMT).

\section{*Sumatria vittata (Peris, 1952)}

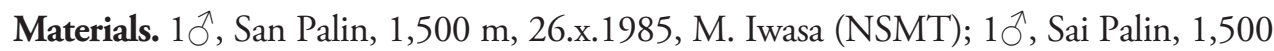
m, 25.x.1985, M. Iwasa (NSMT); 10 , Sai Palin, 1,500 m, 25.x.1985, M. Iwasa (NSMT). 


\section{Acknowledgements}

We would like to thank K. Harusawa, Y. R. Huang, W. H. Lin, Y. J. Liu, T. R. Tsai, T. H. Wu, and Y. C. Yu, for helping to collect the specimens. We thank A. Shinohara and M. Tomokuni of the National Museum of Nature and Science, Tokyo, for helping to examine the specimens. Thanks also to T. Hayashi, K. Sawabe, and Y. Tsuda of the National Institute of Infectious Diseases of Japan, and W. J. Wu of the Department of Entomology, National Taiwan University for assistance during this study. We thank K. Rognes for helping to identify specimens and providing suggestion. Thanks to Buford Pruitt for revising this article. This work was supported by the National Science Council, Taiwan (NSC100-2631-H-002-018 and NSC102-2917-I-002-005).

\section{References}

Catts EP, Goff ML (1992) Forensic entomology in criminal investigations. Annual Review of Entomology 37: 253-272. doi: 10.1146/annurev.en.37.010192.001345

Dag A, Gazit S (2001) Mango pollinators in Israel. Journal of Applied Horticulture 2: 39-43. Fan Z (1992) Key to the common flies of China, Second Edition. Science Press, Beijing, 992 pp. Hennig W (1941) Verzeichnis der Dipteren von Formosa. Entomologische Beihefte 8: 1-239. James MT (1977) Family Calliphoridae. In: Delfinado MD, Hardy DE (Eds) A catalog of the

Diptera of the Oriental Region. Volume III. Suborder Cyclorrhapha (excluding Division Aschiza). The University Press of Hawaii, Honolulu, 526-556

Kano R, Shinonaga S (1968) Calliphoridae (Insecta: Diptera). Biogeographical Society of Japan, Tokyo, $181 \mathrm{pp}$.

Kurahashi H (1970) Tribe Calliphorini from Australian and Oriental regions, I. Melindagroup (Diptera: Calliphoridae). Pacific Insects 12: 519-542.

Kurahashi H (1987a) Blow flies of medical importance in Taiwan (Diptera: Calliphoridae) 1. Tribes Calliphorini and Luciliini. Sieboldia Supplement: 47-59.

Kurahashi H (1987b) The blow flies of new guinea, Bismarck Archipelago and Bougainville Island (Diptera: Calliphoridae). Entomological Society of Japan, Occational Publications, no. 1. Tokyo, 99 pp.

Kurahashi H (2000) On two undescribed species of Protocalliphora from Taiwan and Kyrgyzstan (Diptera: Calliphoridae). Insects and Nature 35: 27-30.

Kurahashi H, Bunchu N (2011) The blow flies recorded from Thailand, with the description of a new species of Isomyia Walker (Diptera, Calliphoridae). The Japanese Journal of Systematic Entomology 17: 237-278.

Kurahashi H, Kano R (1995) A new Luciliine blow fly (Diptera, Calliphoridae) from Taiwan. Special Bulletin of the Japanese Society of Coleopterology 4: 487-490.

Rognes K (1991) Blowflies (Diptera, Calliphoridae) of Fennoscandia and Denmark. Fauna Entomologica Scandinavica, Volume 24. E. J. Brill, Leiden, 272 pp.

Rognes K (1997) The Calliphoridae (blowflies) (Diptera: Oestroidea) are not a monophyletic group. Cladistics 13: 27-66. doi: 10.1111/j.1096-0031.1997.tb00240.x 
Rognes K (2002) Blowflies (Diptera, Calliphoridae) of Israel and adjacent areas with a new species from Tunisia. Entomologica Scandinavica Supplements 59: 1-148.

Rognes K (2009a) The identity of Pollenoides kuyanianus Matsumura, 1916 (Diptera: Calliphoridae: Bengaliinae). Insecta Matsumurana, New Series, 65: 93-100.

Rognes K (2009b) Revision of the Oriental species of the Bengalia peuhi species-group (Diptera: Calliphoridae). Zootaxa 2251: 1-76.

Rognes K (2011a) A review of the monophyly and composition of the Bengaliinae with the description of a new genus and species, and new evidence for the presence of Melanomyinae in the Afrotropical Region (Diptera, Calliphoridae). Zootaxa 2964: 1-60.

Rognes K (2011b) The identity of the frog fly Caiusa coomani Séguy, 1948 (Diptera, Calliphoridae). Zootaxa 2735: 28-30.

Sawabe K, Hoshino K, Isawa H, Sasaki T, Hayashi T, Tsuda Y, Kurahashi H, Tanabayashi K, Hotta A, Saito T, Yamada A, Kobayashi M (2006) Detection and isolation of highly pathogenic $\mathrm{H} 5 \mathrm{~N} 1$ avian influenza A viruses from blow flies collected in the vicinity of an infected poultry farm in Kyoto, Japan, 2004. The American Journal of Tropical Medicine and Hygiene 75: 327-332.

Senior-White R, Aubertin D, Smart J (1940) The Fauna of British India, including Remainder of the Oriental region. Diptera VI. Faimily Calliphoridae. Taylor and Francis Limited Company, London, 288 pp.

Singh KI, Kurahashi H, Kano R (1979) A preliminary key to the common calliphorid flies of Peninsular Malaysia (Insecta: Diptera). The Bulletin of Tokyo Medical and Dental University 26: 5-24.

Triplehorn CA, Johnson NF (2005) Borror and Delong's Introduction to the Study of Insects. Thomson Brooks/Cole, CA, 864 pp.

Tumrasvin W, Kurahashi H, Kano R (1979) Studies on medically important flies in Thailand VII. Report on 42 species of calliphorid flies, including the taxonomic keys (Diptera: Calliphoridae). The Bulletin of Tokyo Medical and Dental University 26: 243-272. 